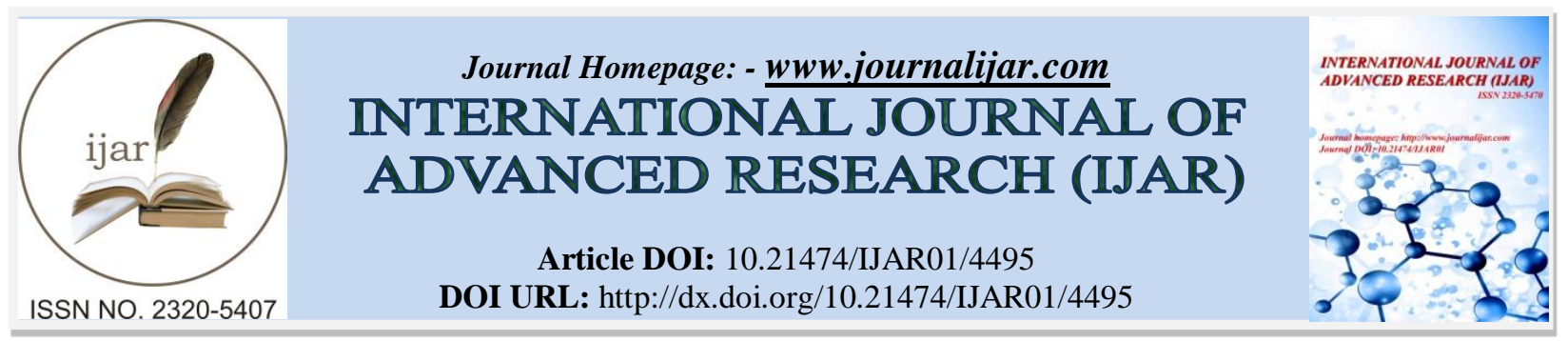

RESEARCH ARTICLE

\title{
BIOGENIC SYNTHESIS OF CUO NANOPARTICLES AND THEIR BIOMEDICAL APPLICATIONS: A CURRENT REVIEW.
}

\author{
"Shakeel Ahmad Khan ${ }^{1}$, Sammia Shahid ${ }^{1}$, Muhammad Rizwan Sajid ${ }^{2}$, Farah Noreen ${ }^{3}$ and Sadia Kanwal ${ }^{4}$. \\ 1. Department of Chemistry, University of Management and Technology Lahore-54000, Pakistan. \\ 2. Department of Physics, University of Agriculture Faislabad-38000, Pakistan. \\ 3. Department of Botany, GC University For Women, Faisalabad-38000, Pakistan. \\ 4. Department of Biochemistry, University of Agriculture Faislabad-38000, Pakistan.
}

\section{Manuscript Info}

\section{Manuscript History}

Received: 15 April 2017

Final Accepted: 17 May 2017

Published: June 2017

Key words:-

$\mathrm{CuO}$, Nanoparticles, Green Synthesis

Leaf Extract, Antioxidant, Antibacterial

Photocatalytic Degradation

\section{Abstract}

In this paper, brief reviews for the synthesis of copper oxide nanoparticles by the different green routes are described. Since last few years, synthesis of nanoparticles has been attracted considerable attention. The metal oxides are important technology materials used as antibacterial, antioxidant, antifungal as well as catalysts in chemical industries and in electronic and photonic devices. Due to the applications in advanced technologies, researchers have focused more on synthesis of $\mathrm{CuO}$ nanoparticles with improved, cost effective ecofriendly synthetic strategies. Copper oxide nanoparticles appear as a brownish-black powder. They can be reduced to metallic copper when exposed to hydrogen or carbon monoxide under high temperature. Copper oxide nanoparticles are used in wide range of applications such as biological, catalysis, gas sensors, magnetic storage media, batteries, solar energy transformer, semiconductors, and field emission. $\mathrm{CuO}$, as a P-type semiconductors exhibiting narrow band gap, have attracted great attention due to its potential application in Nano devices such as electronic, optoelectronics.

Copy Right, IJAR, 2017,. All rights reserved.

\section{Introduction:-}

During the last few decades, the interests of scientists are increasing continuously day by day in the field of science and technology at the nanometer range. Nano-science and nanotechnology is supposed to wrap all fields of science and technology because any material particle is made up of atoms and molecules [1]. In science and technology, was considered well-progressed interdisciplinary field of research in last few year. Particularly metal oxide nanoparticles have extensive well-known their application of in many fields of science including chemical industry, electronics, biomedical sciences, biosensor, molecular catalysts, magnetic materials and drug gene delivery due to their physical and chemical properties different from those in the bulk material [2]. Main focus of nanoscience and nanotechnology is synthesis of new nanoparticles with various sizes and new morphology. Due to change in morphology strongly effects on their broadly varying properties. Much attention attracted by nanoparticles on account of their unique properties and energetic application which are strongly influenced by their size, morphology and structure. Cupric oxide nanomaterials have attracted much attention on account of their distinctive properties among other metal oxides nanomaterials [3]. Cupric oxide nanoparticles have got great consideration because it is 
the simplest member of the family of copper salt and shows a range of possibly useful physical properties such as electron correlation effects, spin dynamics and high temperature superconductivity.

Cupric oxide has shown wide applications in the fields which range from energy conversion and storage, environmental science electronics, and sensor. Cupric oxide is a p-type semiconductor material which has a narrow band gap of $1.2 \mathrm{eV}$. In the last few years, they are getting much attention for their unique properties and potential applications as heterogeneous catalysts, lithium ion batteries, gas sensors, antibacterial agents and solar cells. In addition, CuO NAPs are robust, stable and their shelf life is longer as compared to organic antimicrobial agents [4]. Colloidal metal and metal oxide nanoparticles of Silver, Gold and cupric oxide have been used extensively in optoelectronic, industrial and biomedical applications. $\mathrm{CuO}$ nanoparticles have monoclinic crystallite structures and due to their versatile physical and chemical properties, they have been used in numerous technical and scientific applications. They have been utilized as antibacterial agent, antioxidant agent, drug delivery agent, and imaging agent in field of biomedicine. In industrial field, they have been used widely as p-type semiconductor materials, transistors, in the construction of batteries, gas sensors, and field emitters. The applications of nanoparticles can be changed depending on the shape and size, which affects physical and chemical properties of cupric oxide nanoparticles directly. In the field of energy saving, by using copper oxide nanoparticles in energy transferring fluids, the viscosity of fluid improves and thus boosts thermal conductivity [5]. There are several methods are in practice to synthesize the $\mathrm{CuO}$ NAPs but the use of plant extracts is gradually evolving research area known as green synthesis of nanoparticles (NAPs). In plant extract mediated synthesis method, some experimental parameters i.e. mass ratio between Copper salt and extract, nature of plant extract, temperature and reaction time, have shown direct influence on the morphology of Copper oxide nanoparticles [6,7].

\section{Green synthesis of $\mathrm{CuO}$ nanoparticles:-}

Human beings have depended on plants for survival since ever [8]. Nature has blessed aerobic organisms with an inner defense system that resists against oxidative damage due to reactive oxygen species [9]. It is well acknowledged that plants are the richest resorts of antioxidants. Plants are to be found significant cradle for energetic natural products which fluctuate extensively in rapports of construction, biological characteristics and mechanism of act [10]. They act as anti-bacterial, anti-oxidant, anti-fungal, anti-carcinogenic, analgesics. Antioxidants comprising compounds are tocopherols, alkaloids, flavonoids, glycosides carotenoids, phenolics compounds and acids [11]. For centuries plants have been castoff as medications for humanoid ailments [12]. Beside this, now day different plants like (Abutilon indicum) are also using for the green synthesis of nanoparticles [13].

Green synthesis is potentially advantageous over chemical or microbial approach as it simplifies the process and also results in production at larger scale [14]. Finding suitable, nontoxic and natural product to prepare metal nanoparticles in an aqueous environment was quite an effort. Several naturally existing materials were utilized to construct nanoparticles but apparently plants seem to outrun the other contenders. Plant origin nanoparticles are much durable, offer various sizes and shapes and moreover their production can be at much faster pace [15]. Green chemistry is about biosynthesis of metal or metal oxide nanoparticles using environment friendly methods. This concept entails avoid using harsh \& toxic reducing agents (eg, hydrazine hydrate, sodium borohydride, dimethylformamide, ethylene glycol, and so on), and expensive chemicals. Many of these reducing agents have been declared major culprits notoriously known as biological hazards and lead to environmental toxicity. For the synthesis of nanomaterials with growing interest is in the reduction or total removal of waste and the implement of appropriate procedures and processes. In these processes, we used major true principles of green chemistry to grow of natural and biomimetic procedures [16]. In the medical application when we have used chemical synthesis methods then these chemical adsorbed on the material surface which have great impact on our lives. In synthesis of nanomaterials different factors effect in the production of high quality nanomaterials with respect to chemical purity, crystallinity, phase selectivity, and homogeneity in dot size and shape with controlled state of accumulation in inexpensive method is still a task to material chemists. Due to increase awareness towards green chemistry and other biological processes, the desire to grow green approach for the preparation of nanoparticles has increased. From plant extract nanoparticles were synthesized which provide environmental friendly atmosphere that deal several benefits of eco-friendliness and compatibility for pharmaceutical material and other biomedical application. They do not utilize poisonous chemicals for the manufacture procedure [17]. Recently, for the development of novel routes to synthesize nanoparticles, the material scientists and researchers have focused on green routes. Greener procedures are eco-friendly, inexpensive, very cheap and without use of harsh chemicals (Sankar, 2013). Based on applied synthesis protocols, in distinctive plant extract facilitated nanoparticles synthesis, the plant extract is mixed with a certain mass ratio metal salts. Nanoparticles are formed and different ranges of temperatures form room temperature 
to hundred degree centigrade. Nanoparticles are formed at different time period that from minutes to hours. Usually, in plant extract great amount metabolites are present such as terpenoids, tannins, flavonoids and proteins that behave reducing and stabilizing agents $[6,19]$.

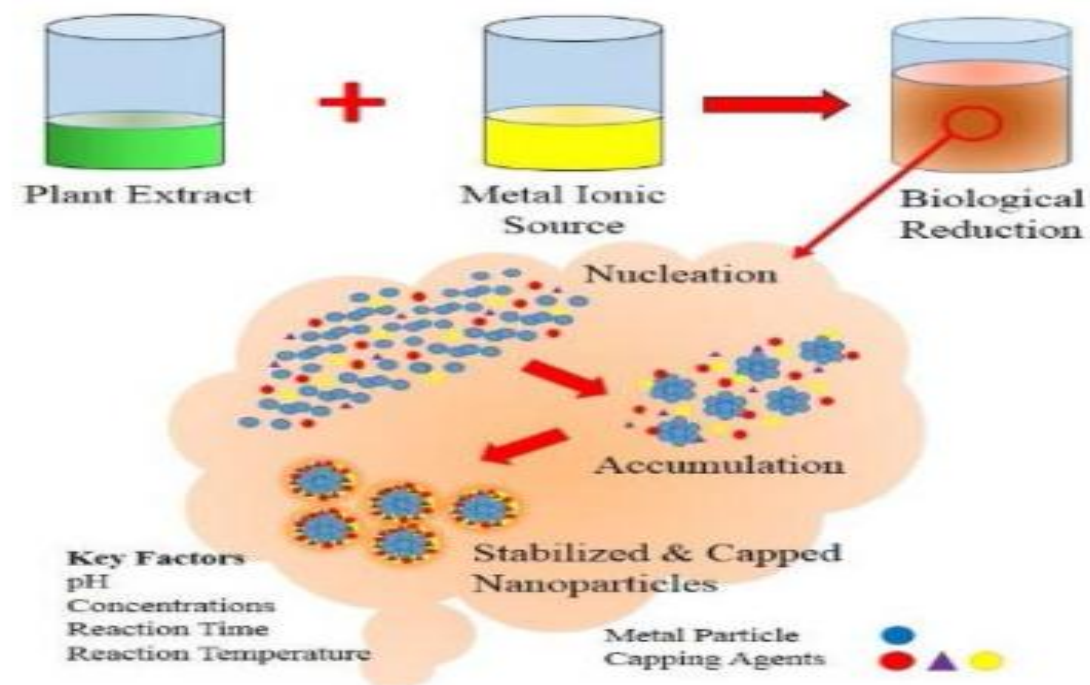

Figure 1:- Green synthesis of $\mathrm{CuO}$ nanoparticles

The primary requirement of green synthesis of CuO NAPs is copper metal ion solution and a reducing biological agent. In most of the cases reducing agents or other constituents present in the cells acts as stabilizing and capping agents, so there is no need of adding capping and stabilizing agents from outside.

\section{Metal Ion Solution:-}

The $\mathrm{Cu}^{++}$ions as well as $\mathrm{O}^{-2}$ ions are primary requirement for the synthesis of $\mathrm{CuO}$ NPs which can be obtained from various water soluble salts of copper. However, the aqueous solution of $\mathrm{Cu}\left(\mathrm{NO}_{3}\right)_{2} \cdot 3 \mathrm{H}_{2} \mathrm{O}$ and $\mathrm{CuSO}_{4} .5 \mathrm{H}_{2} \mathrm{O}$ with $\mathrm{Cu}^{++}$ ion concentration range between $0.1-10 \mathrm{~mm}$ (most commonly $1 \mathrm{~mm}$ ) has been used by the majority of researchers.

\section{Biological reducing Agents:-}

The reducing agents are widely distributed in the biological systems [6]. The CuO NAPs have been synthesized using different plants under different conditions [13]. Data are not available regarding use of animal materials for the synthesis of $\mathrm{CuO}$ NAPs till date to the best of our knowledge. Due to this limitation, green synthesis of $\mathrm{CuO}$ NAPs has been discussed under headings plants, and bio-polymers. Green syntheses of CuO NAPs have been performed by using plant extracts, microbial cell biomass or cell free growth medium and biopolymers [3]. The plants used for $\mathrm{CuO}$ NAPs synthesis range from algae to angiosperms; however, limited reports are available for lower plants and the most suitable choice are the angiosperm plants [4].

Leaf, bark, root, and stem of plants have been used for the CuO NAPs synthesis [6,7]. The medicinally important plants like Carica papaya [6], T. arjuna [7], Abutilon indicum [13], Clove [20], Gum karaya [21], Matricaria chamomilla [22], Gloriosa superba [23], Albizia lebbeck [24], Aloe vera [25], Rauwolfia serpentine [26], Cissus quadrangularis [27], Tinospora cordifolia [28], Malva sylvestris [29], Rubus glaucus [30], Phyllanthus Amarus [31], Bifurcaria bifurcate [32], Tabernaemontana divaricate [33] etc. have been used for the green synthesis of CuO NAPs. Some exotic weeds like Tridax procumbens [34] growing in uncontrolled manner due to lack of natural enemies and causing health problems have also been used for $\mathrm{CuO}$ NAPs synthesis. The other group includes alkaloids (Carica papaya) and essential oils (Mentha piperita) producing plants [35]. All the plant extracts played dual role of potential reducing and stabilizing agents with an exception in few cases where external chemical agents like sodium-do-decyl sulphate were used for stabilization of the CuO NAPs [36]. Metabolites, proteins and chlorophyll present in the plant extracts were found to be acting as capping agents for synthesized CuO NAPs [37]. The preferred solvent for extracting reducing agents from the plant is water in most of the cases however, there are few reports regarding the use of organic solvents like methanol [35], ethanol [36] and ethyl acetate [37]. Some researchers pre-treated the plants materials in saline [32] or acetone [33] atmospheres before extraction. On the 
whole, even though the extracting solvents differed, the nanoparticle suspensions have made in aqueous medium only. Synthesis using plant extracts generate nanoparticles of well-defined shape, structure and morphology in compared to those obtained through the utilization of bark, tissue and whole plant [38]. No special capping agent was used in the work of many researchers for stabilizing the synthesized CuO NAPs, Among the wide varieties off bio-polymers used for $\mathrm{CuO}$ NAPs synthesis, almost all played the dual role of reducing and stabilizing agents with an exception of using starch as a capping agent [39].

\section{Separation of $\mathrm{CuO}$ NAPs:-}

Centrifugation technique is mostly used by researchers to obtain the pellet or powder form of synthesized silver nanoparticles [31]. The CuO NAPs suspensions were also oven dried to obtain the product in powder form [32]. Some common characterizations of CuO NAPs include UV-Vis Spectra, SEM, TEM, FTIR, XRD and EDAX or EDX/EDS. DLS study is mostly used for CuO NAPs synthesized from bio-polymers rather than plant extracts and microorganisms. Zeta potential values indicate the stability of synthesized CuO NAPs. Thermo-Gravimetric Analysis (TGA) is used to find the effect of $\mathrm{Cu}(\mathrm{NO})_{3} \cdot 3 \mathrm{H}_{2} \mathrm{O}$ and L-cystine on the organic composition of $\mathrm{CuO}$ NAPs [58] to find out the amount of organic material in synthesized CuO NAPs [33] and predict the thermal stability of CuO NAPs [34]. Inductive Coupled Plasma (ICP) analysis was performed to analyze the concentration and conversion of $\mathrm{CuO}$ NAPs [13].

\section{Monitoring of CuO NAPs:-}

The appearance of slight brownish to dark brownish color in the colorless solution has been taken as indicative of $\mathrm{CuO}$ NAPs synthesis by almost all the researchers [20]. The SPR peak of the synthesized CuO NAPs was witnessed in the range of 400-450 nm, the significant range for CuO NAPs [21]. The UV-Vis spectral analyses have been used to analyze the dependency of $\mathrm{pH}$, metal ion concentration, extract content on the formation of CuO NAPs and reveal the size-stability of synthesized $\mathrm{CuO}$ NAPs by exhibiting red shift in the SPR peak with increase in size of nanoparticles and blue shift for decrease in size [23]. The SEM morphological analysis in most of the studies revealed spherical structure for CuO NAPs [24]. Some studies also revealed the flower as well as cube structure for the $\mathrm{CuO}$ NAPs. Using XRD studies of almost all the researchers reported the formation of hexagonal wurtzite crystalline structured of $\mathrm{CuO}$ NAPs $[13,25]$. EDS or EDAX, for analyzing elemental composition in the nanomaterials, exhibited a characteristic optical absorption band peak around 2-3 $\mathrm{KeV}$ with $\mathrm{Cu}$ and $\mathrm{O}$ weight percentage ranging from $45 \%$ to $80 \%$ [13]. The reported stability of synthesized CuO NAPs has varied from 1 day to 1 year depending upon reducing agents and other operating conditions [29].

\section{Factors affecting CuO NAPs synthesis:-}

The major physical and chemical parameters that affect the synthesis of $\mathrm{CuO}$ NAPs are reaction temperature, metal ion concentration, extract contents, $\mathrm{pH}$ of the reaction mixture, duration of reaction and agitation [40]. Parameters like metal ion concentration, extract composition and reaction period largely affect the size, shape and morphology of the $\mathrm{CuO}$ NAPs [41]. Most of the authors have reported suitability of basic medium for CuO NAPs synthesis due to better stability of the synthesized nanoparticles in basic medium [13,31,35,40]. Some other advantages reported under basic $\mathrm{pH}$ are rapid growth rate [21,25,27,33,41], good yield and mono dispersity and enhanced reduction process [42]. Small and uniform sized nanoparticles were synthesized by increasing $\mathrm{pH}$ of the reaction mixture [43]. The nearly spherical CuO NAPs were converted to spherical CuO NAPs by altering pH [44]. However, very high $\mathrm{pH}(\mathrm{pH}>11)$ was associated with the drawback of formation of agglomerated and unstable CuO NAPs [41].

The reaction conditions like time of stirring and reaction temperature are important parameters. Temperatures up to $37-400^{\circ} \mathrm{C}$ were used by many researchers for $\mathrm{CuO}$ NAPs synthesis using plant extracts. The temperature increase $\left(37^{\circ} \mathrm{C}-400^{\circ} \mathrm{C}\right)$ resulted in increased rate of $\mathrm{CuO}$ NAPs synthesis [45] and also promoted the synthesis of smaller size $\mathrm{CuO}$ NAPs [46]. On the whole, most of workers have synthesized $\mathrm{CuO}$ NAPs at room temperature $\left(25^{\circ} \mathrm{C}\right.$ to $\left.37^{\circ} \mathrm{C}\right)$ range. It has been found that the size range of $\mathrm{CuO}$ NAPs synthesized from algae, bryophytes, gymnosperms and bio-polymer sources lie below $50 \mathrm{~nm}$ and that of $\mathrm{CuO}$ NAPs synthesized using from angiosperms sources ranged between $100 \mathrm{~nm}$ and more. The reaction mixture synthesizing $\mathrm{CuO}$ NAPs using bio-polymers were continuously agitated to protect agglomeration compared to plant extracts without any suitable reason by the authors. Reaction mixture agitation achieved by applying external mechanical force might accelerate the formation of nanoparticles. Aging of the synthesized CuO NAPs solution changed spherical nanoparticles into flower like structure $[47,48,49]$. 


\section{Applications of CuO NAPs:-}

The recent research results have shown that the CuO NAPs, due to their special characteristics, have immense potential for applications as anti-microbial, anti-parasitic and anti-fouling agents; as agents for site-specific medication, water purification systems, etc. The essential features of some of these applications are discussed in the following sections.

\section{Anti-microbial Activity:-}

The CuO NAPs have been found to exhibit promising anti-microbial activity in contrast to chemical synthesized $\mathrm{CuO}$ NAPs. Researchers have used several novel techniques to confirm and quantify the anti-microbial activity of $\mathrm{CuO}$ NAPs. Different microbial strains from gram positive i.e. E. coli etc. to gram negative i.e. B. subtilis, Staphylococcus aureus, Klebsiella have used in this activity by researchers.

\section{Disc/Well Diffusion Methods:-}

The disc diffusion method, a most commonly used technique to access the antimicrobial activity of a liquid, has been employed by many researchers to confirm antimicrobial action of the green synthesized CuO NAPs solution. In this method, uniform sized disc of adsorbent material are dipped in the increasing concentration of green synthesized $\mathrm{CuO}$ NAPs and placed over surface of the targeted microbe inoculated on the nutrient medium plates. An inhibition zone formation around the disc reflects antimicrobial action of the nanomaterials. Literature study revealed that superior antimicrobial activity of green synthesized $\mathrm{CuO}$ NAPs was due to the fact that the copper ions released form $\mathrm{CuO}$ nanoparticles permeated the bacterial cell membrane and destroyed the structure of the cell membrane by attaching to the negatively-charged cell wall $[6,13]$. Copper ions are involved in cross-linkage of nucleic acid strands by binding them with DNA molecule of bacteria. This results in a disordered helical structure of DNA molecule which causes denaturation of proteins and some other biochemical processes in the cell, leading to complete destruction of the bacterial cell [13]. Factors which affect the sensitivity of bacteria to copper oxide nanoparticle are size of particles, temperature of synthesis of the nanoparticles, structure of bacterial cell wall, and degree of contact of the nanoparticles with bacteria $[6,13]$.

\section{Antioxidant Activity:-}

The green synthesized $\mathrm{CuO}$ NAPs have been found to exhibit promising antioxidant activity. Researchers have used several novel techniques to confirm and quantify the antioxidant activity of green synthesized CuO NAPs [13]. Different methods i.e. DPPH radical scavenging assay, ferric reducing antioxidant power (FRAP) assay, total antioxidant assays, ferric thiocyanate (FTC) and total phenolic content (TPC) assays have applied for the evaluation of antioxidant activity of green synthesized $\mathrm{CuO}$ NAPs by researchers. All antioxidant assays results demonstrated remarkable antioxidant potential of green synthesized $\mathrm{CuO}$ NAPs in contrast to chemical synthesized $\mathrm{CuO}$ NAPs.

\section{Photocatalytic degradation Activity:-}

The photocatalytic degradation activity of green synthesized $\mathrm{CuO}$ nanoparticles were estimated by the degradation of different commercial grade organic based dyes that were employed as effluents [13,28,35,37,41]. Different organic based dyes i.e. Acid Black 210, Methylene Blue, Methylene Red etc. were disintegrated by green synthesized $\mathrm{CuO}$ NAPs. Their activity was checked by changing the $\mathrm{pH}$, changing the light medium from $\mathrm{UV}$ to sunlight. UV-Visible spectrophotometer instrument was used in this activity by the all researchers. The disintegration of organic dye takes place as follows,

Copper oxide + light $\rightarrow$ electron + hole

Electron + oxygen molecule $\rightarrow$ Super oxide free radical

Hole + Hydroxyl ion $\rightarrow$ Hydroxyl free radical

Hole + Water $\rightarrow$ Proton + Hydroxyl free radical

Hydroxyl free radical + Dye $\rightarrow$ Product of Degradation

Oxygen molecule free radical + Dye $\rightarrow$ Product of Degradation

In the first step, green synthesized copper oxide nanoparticles come in contact with light. It creates a photogenerated electron and a hole. This photo-generated electron reacts with oxygen molecule to form super oxide free radical in the second step. In the third step, hole reacts with water and hydroxyl ions to produce highly mercurial hydroxyl radicals. These superoxide free radicals and hydroxyl free radicals' reacts violently with the organic dye and decompose/ decolorize it in the next step. The degradation/decomposition rate of the organic dye totally depends upon morphological and crystal structure of photochemical catalyst. Active sites of photo-catalyst can be increased 
by increasing the surface area and crystallinity which in turn increase the effectiveness of photocatalytic reactions by separating electron-hole pairs. Literature revealed that $\mathrm{CuO}$ nanoparticles completely disintegrated the organic dye into their respective disintegrated products i.e. $\mathrm{NH}_{3}, \mathrm{SO}_{2}, \mathrm{CO}_{2}$ and $\mathrm{H}_{2} \mathrm{O}$. The high disintegrative capacity of the $\mathrm{CuO}$ nanoparticles is due to their crystalline nature, because studies have shown that the higher the crystalline nature, the higher the disintegrative ability and the disintegration rate [[13,28,35].

\section{Summary for the Green synthesis of CuO Nanoparticles:-}

Ijaz et al., [13] described the synthesis of copper oxide (CuO) nanoparticles using an ecofriendly technique and were evaluated their antimicrobial, antioxidant and photo-catalytic dye degradation potentials. A superficial method (solution combustion method) was employed for the synthesis of copper oxide nanoparticles from an aqueous extract of Abutilon indicum. The $\mathrm{CuO}$ nanoparticles were characterized using x-ray diffraction (XRD), energydispersive x-ray spectroscopy (EDX), scanning electron microscope (SEM) and ultraviolet-visible (UV-Vis) spectroscopic techniques. The antimicrobial activity of the $\mathrm{CuO}$ nanoparticles was determined by agar well diffusion method, while their antioxidant properties were assessed by DPPH radical scavenging, ferric reducing antioxidant power (FRAP), total antioxidant, ferric thiocyanate (FTC) and total phenolic content (TPC) assays. The photocatalytic degradation activity of synthesized $\mathrm{CuO}$ nanoparticles was assessed by the degradation of Acid Black 210 (AB) dye under sunlight irradiation. XRD, EDX and SEM results confirmed the successful synthesis of $\mathrm{CuO}$ nanoparticles of $16.78 \mathrm{~nm}$ sizes, with hexagonal, wurtzite and sponge crystal structure. Photo-catalytic data revealed that the nanoparticles are a good catalyst for effective degradation of Acid Black 210. The nanoparticles also exhibited remarkable antioxidant activity, with $\mathrm{IC}_{50}$ and FRAP values ranging from $40 \pm 0.23$ to $84 \pm 0.32 \mu \mathrm{g} / \mathrm{ml}$, and $0.65 \pm 0.01$ to $9.10 \pm 0.21$ Trolox equivalent $/ \mathrm{mL}$, respectively. Significant bactericidal activity was manifested by the $\mathrm{CuO}$ nanoparticles against Klebsiella and Bacillus subtilis with zone of inhibition of $14 \pm 0.05$ and $15 \pm 0.11$ $\mathrm{mm}$, respectively. The synthesized $\mathrm{CuO}$ nanoparticles exhibit antibacterial and antioxidant potential, indicating that they are good candidates for future therapeutic applications.

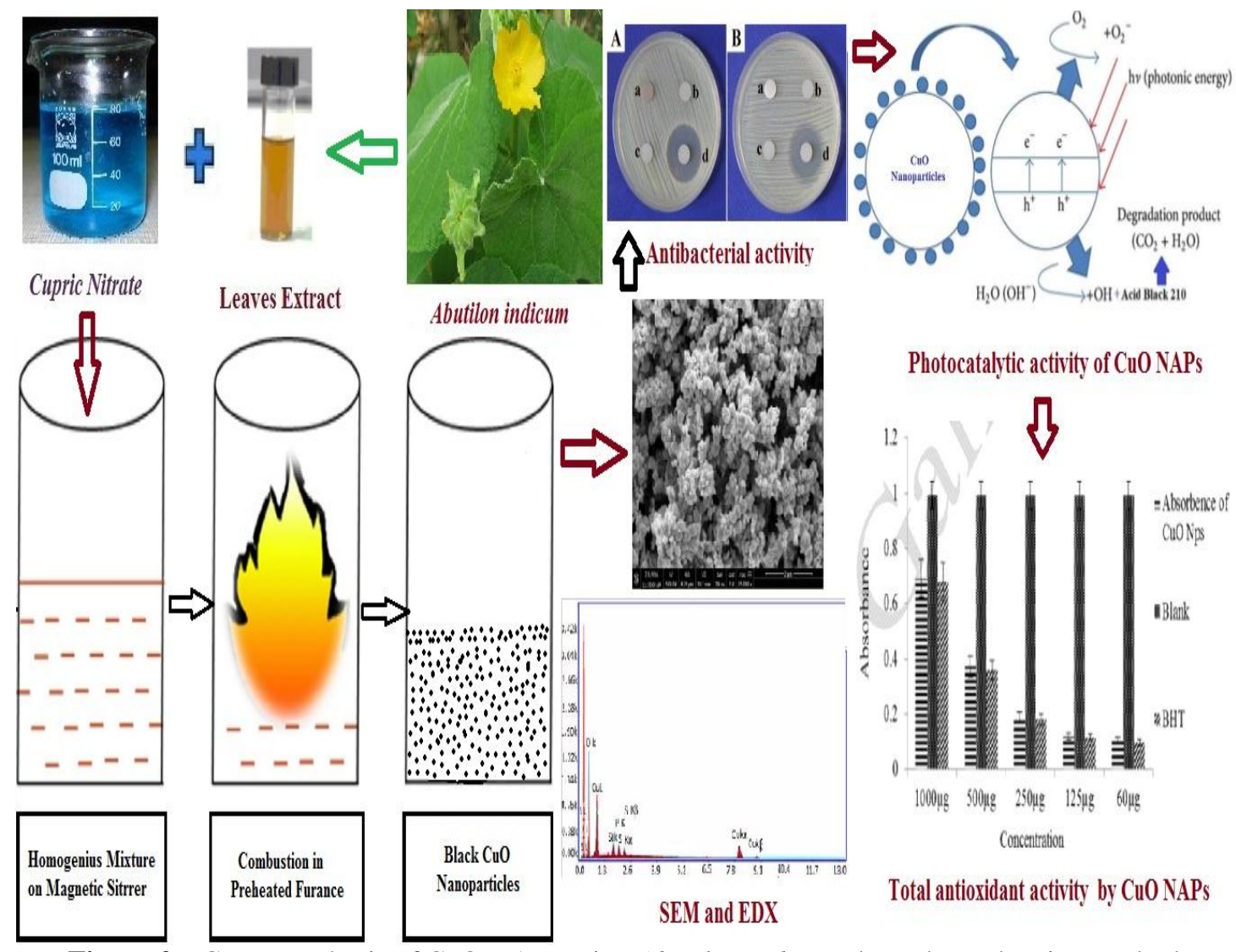

Figure 2:- Green synthesis of CuO NAPs using Abutilon indicum through combustion method. 
Fatih et al., [22] investigated that when extract of medicinal plant (Matricaria chamomilla) was used, the fabrication of copper oxide nanoparticles (CuO NPs) showed both reducing and capping agent. They also investigated the antioxidant properties of the nanoparticles and their interface with DNA plasmid. For the determination of chemical characterization and morphology of nanoparticles, different techniques were used e.g. UV-Vis spectroscopy, FTIR, DLS, XRD, EDX, SEM etc. The CuO NPs exhibited diameter of $140 \mathrm{~nm}$ size. The shape of such type of particles is spherical or somewhat mono-distributed.

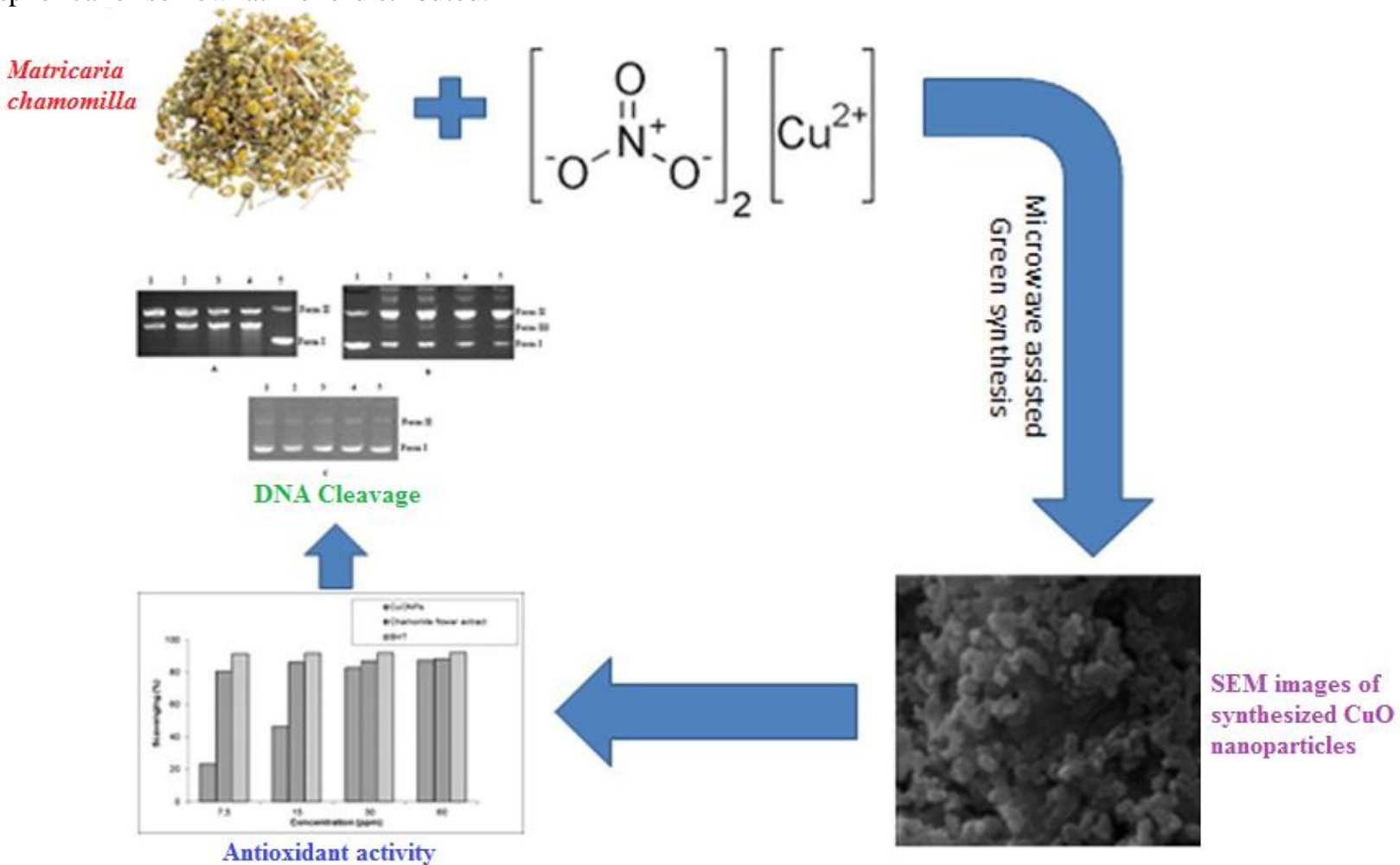

Figure 3:- Microwave assisted green fabrication of CuO NPs using M. chamomilla

Gowdhami et al., [27] studied the antibacterial activity of greenly synthesized $\mathrm{CuO}$ nanoparticles by the stem extract of plant Cissus quadrangularis. The characterization of nanoparticles were synthesized by UV-Vis spectroscopy, SEM, XRD, FTIR and further subjected for antibacterial activity against the pathogens S. aureus, E.coli, K. pneumoniae, $P$. aeruginosa, S. typhi, S. dysenteries and V. cholera. The synthesized particles had the hexagonal and cubic in shape. The diameter of these particles was about $58 \mathrm{~nm}$ according to their SEM photograph. The product obtained existed in pure phase as it is confirmed from XRD results. Intensive peaks are seen with blue shifts in them when the spectrum was observed using FTIR, which indicated structure crystalline and shorten the distance of lattice. They deduced that these NAPs showed a great resistance against all the pathogen tested The nanoparticles used in pharmaceutical industry as bactericide, disinfectant and germ killer, and make this method of green synthesis are reliable method for large scale synthesis of inorganic materials. 


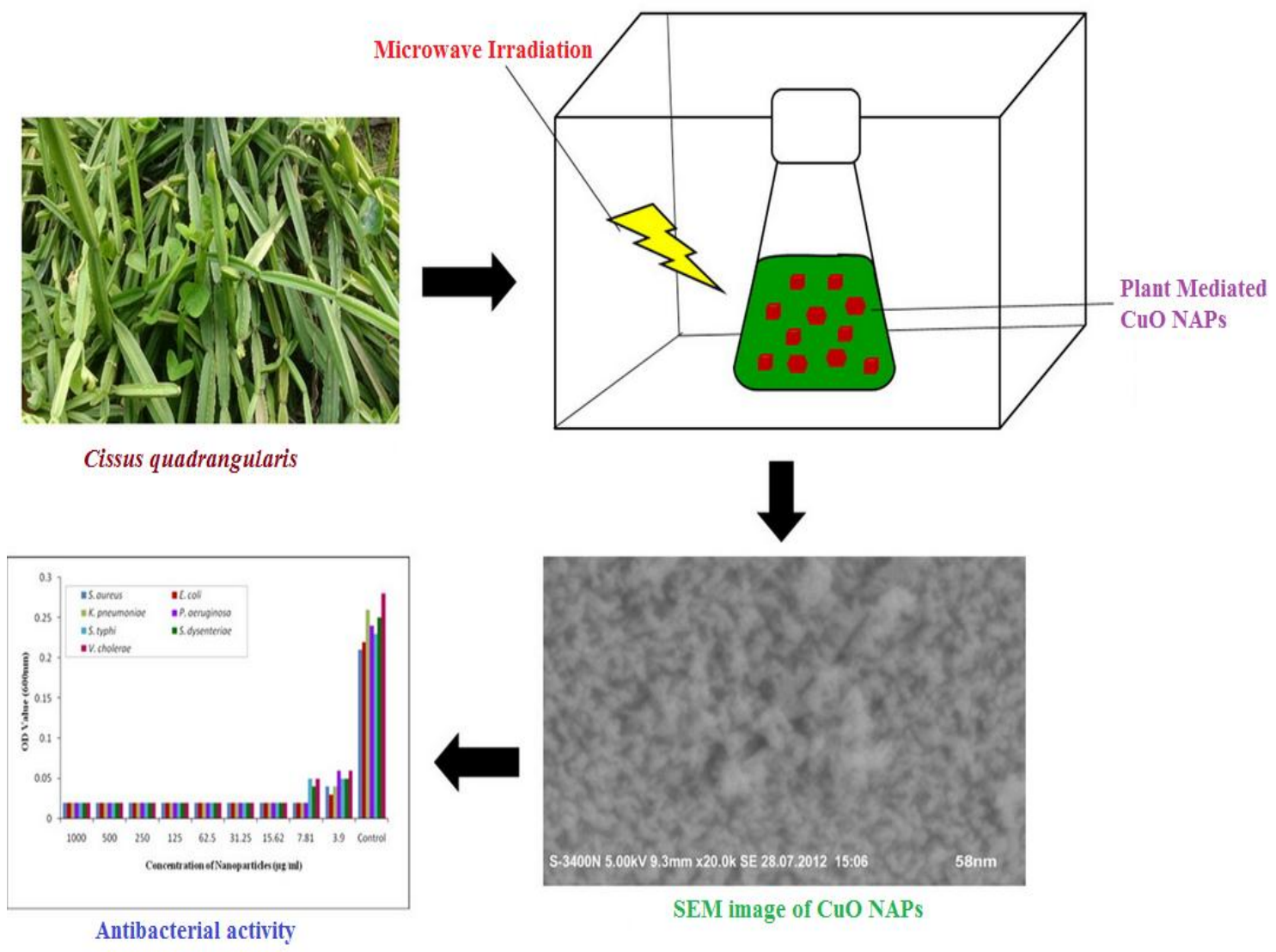

Figure 4:- Microwave irradiated green synthesis of CuO NAPs using Cissus quadrangularis

Naika et al., [23] explained the solution combustion method. This is a greener process because Gloriosa superba $L$. extract used as fuel to synthesize cupric oxide nanoparticles. Monoclinic nature of copper oxide nanoparticles were analyzed by XRD. Blue shift value cupric oxide nanoparticles were measured from UV-Visible absorption spectrum. $\mathrm{CuO}$ nanoparticles are spherical in nature was confirmed with the help of SEM images. Transmission electron microscope characterized the size of copper oxide nanoparticles in the range of 5-10 $\mathrm{nm}$. Cupric oxide nanoparticles were efficiently showed antimicrobial application against pathogenic microbial strains namely $K$. aerogenes, $P$. desmolyticum and E.coli are Gram negative and $S$. aureus are Gram positive bacteria. 


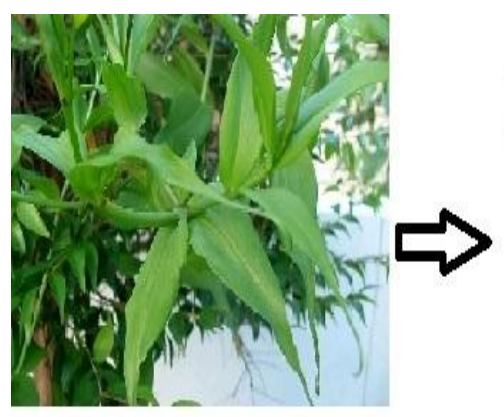

Gloriosa superba
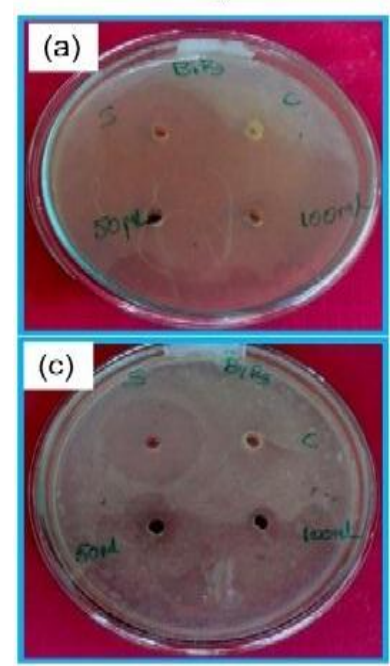

Antibacterial activity
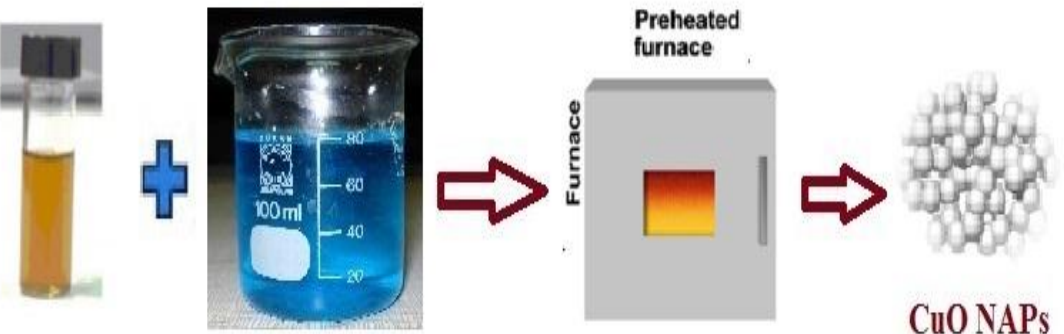

Cu0 NAPs

Cupric Nitrate

Figure 5:- Muffle furnace irradiated green synthesis of CuO NAPs using Gloriosa superba

Jayakumarai et al., [24] used the leaf extract of Albizia lebbeck for the green synthesis of copper oxide nanoparticles which was very simple, effective and rapid research. The synthesized CuO NPs were characterized by using SEM, EDS, TEM, XRD and UV-Vis spectroscopy. The size of copper oxide nanoparticles is less than $100 \mathrm{~nm}$ and they all are spherical in shape. It was proved by them that the extract of A. lebbeck leaves can be used as a cheap and effective reducing agent for the bulk production of $\mathrm{CuO}$ NPs. 


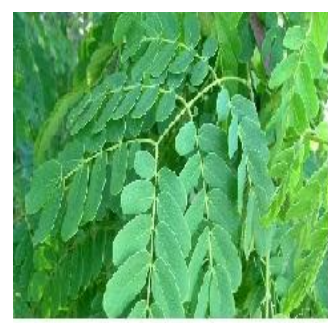

Albizia lebbeck

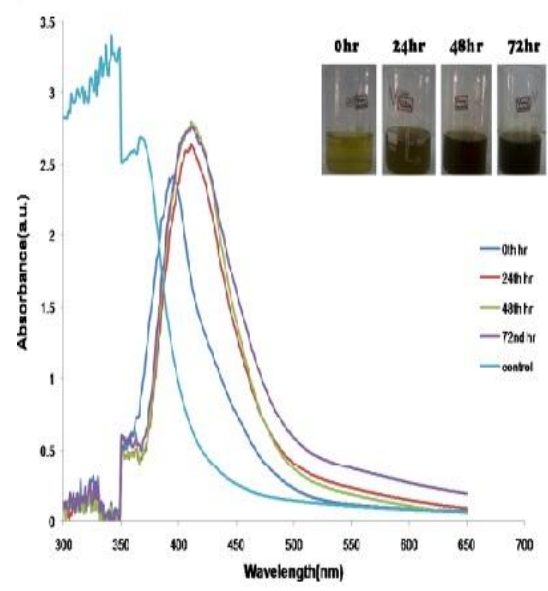

UV-Vis spectra of $\mathrm{CuO}$ NAPs

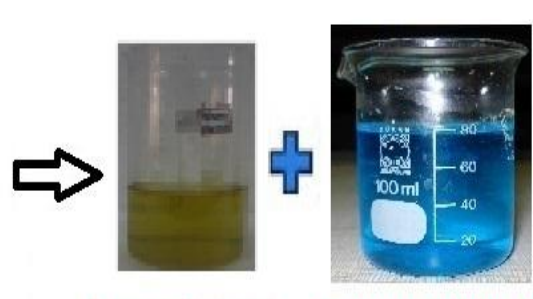

Leaves Extract Copper Sulphate

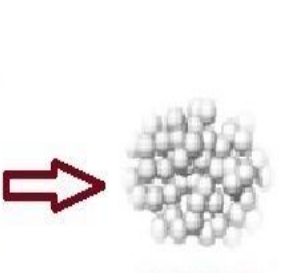

CuO NAPs

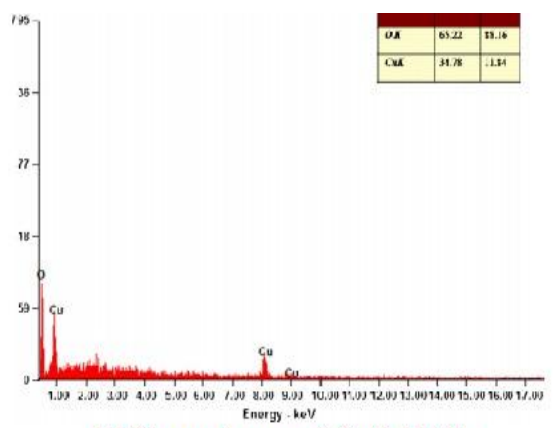

EDX spectrum of CuO NAPs

Figure 6:-Green synthesis of CuO NAPs using Albizia lebbeck

Kumar et al., [25] reported green approach to synthesize of cupric oxide nanoparticles. This is biological and ecofriendly method. They fabricated them using harmless Aloe vera leaf extract. (PXRD) and TEM were used for the characterization. These fabricated particles were found in monoclinic phase with average particle size of $20 \mathrm{~nm}$. They also showed the enhanced antibacterial activity of these nanoparticles against some bacteria which cause serious infections in fish e.g. A. hydrophila, P. fluorescens and F. branchiophilum even at lower concentrations. 

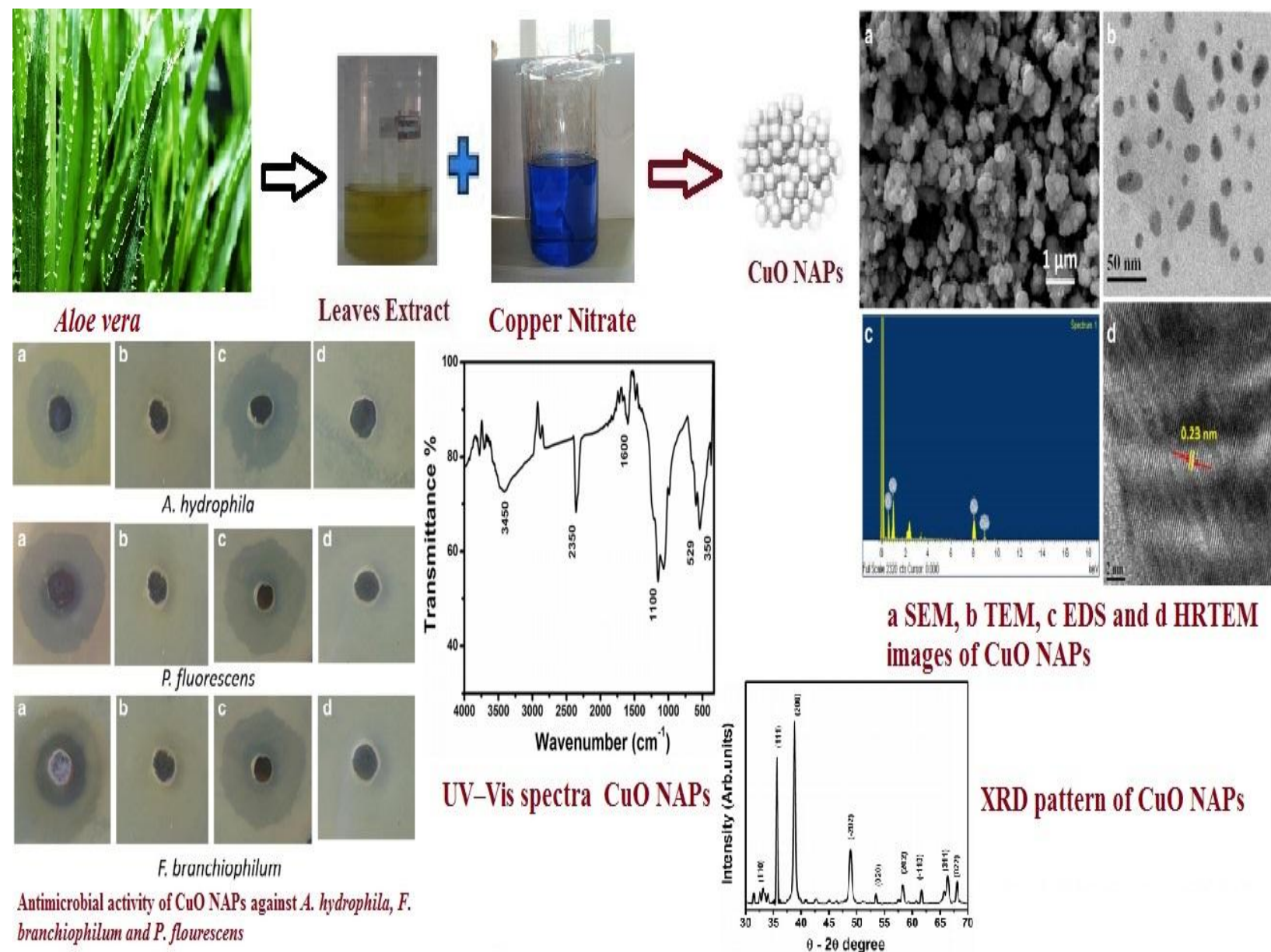

Copper Nitrate

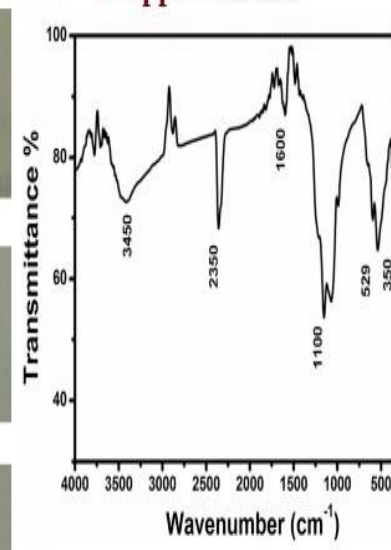

UV-Vis spectra Cu0 NAPs

Figure 7:- Green synthesis of CuO NAPs using Aloe vera

The method of solution combustion was studied by Lingaraju et al., [26] for the synthesis of Copper oxide nanoparticles. The extract of aqueous leaf of Rauwolfia serpentina was used as fuel for combustion. PXRD, SEM, UV-visible, and TEM were used for characterization and morphology of the nanoparticles. They produced monoclinic crystals as revealed by PXRD patterns. Large surface area of sponge-like image was shown by SEM. Agar well method of diffusion was used for the antibacterial properties of $\mathrm{CuO}$ nanoparticles against Gram negative E. coli (NCIM-5051) and P. desmolyticum (NCIM-2028) and Gram positive bacteria S. aureus (NCIM- 5022). 

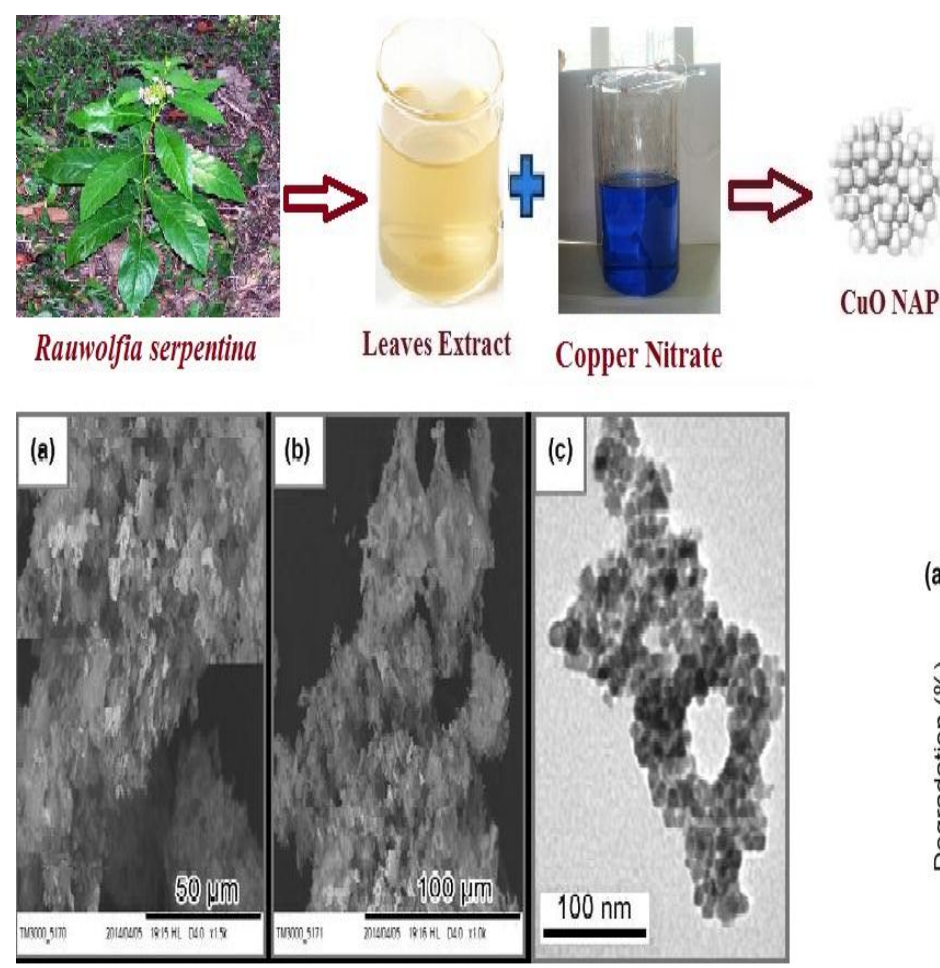

SEM images (a, b) \& TEM image (c) of the synthesized Cu0 NAPs

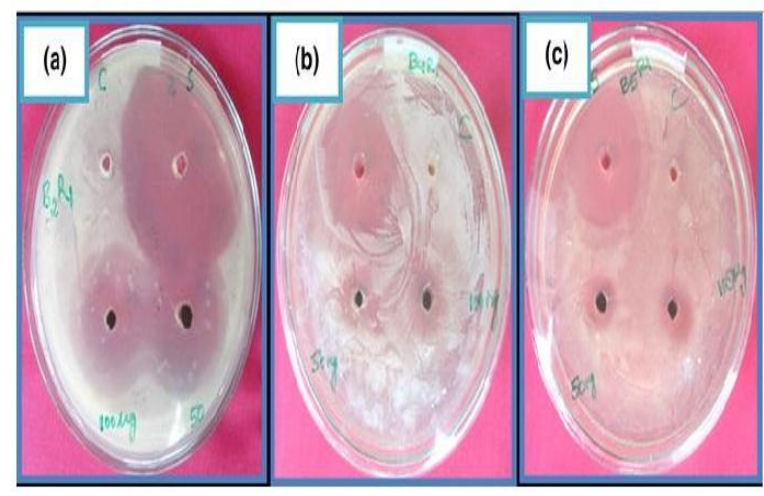

Antibacterial activity of Cu0 NAPs against: (a) E. coli; (b) $S$. aureus; (c) P.desmolyticum
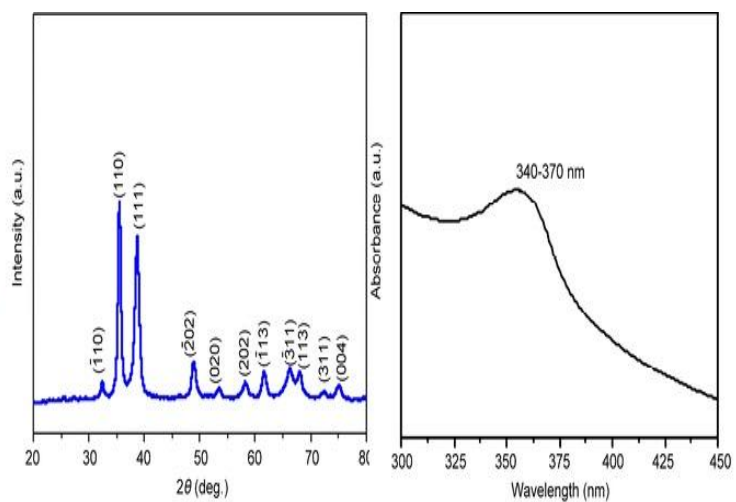

PXRD pattern of the $\mathrm{Cu} 0$ NAPs UV-Vis spectrum of $\mathrm{Cu} 0$ NAPs
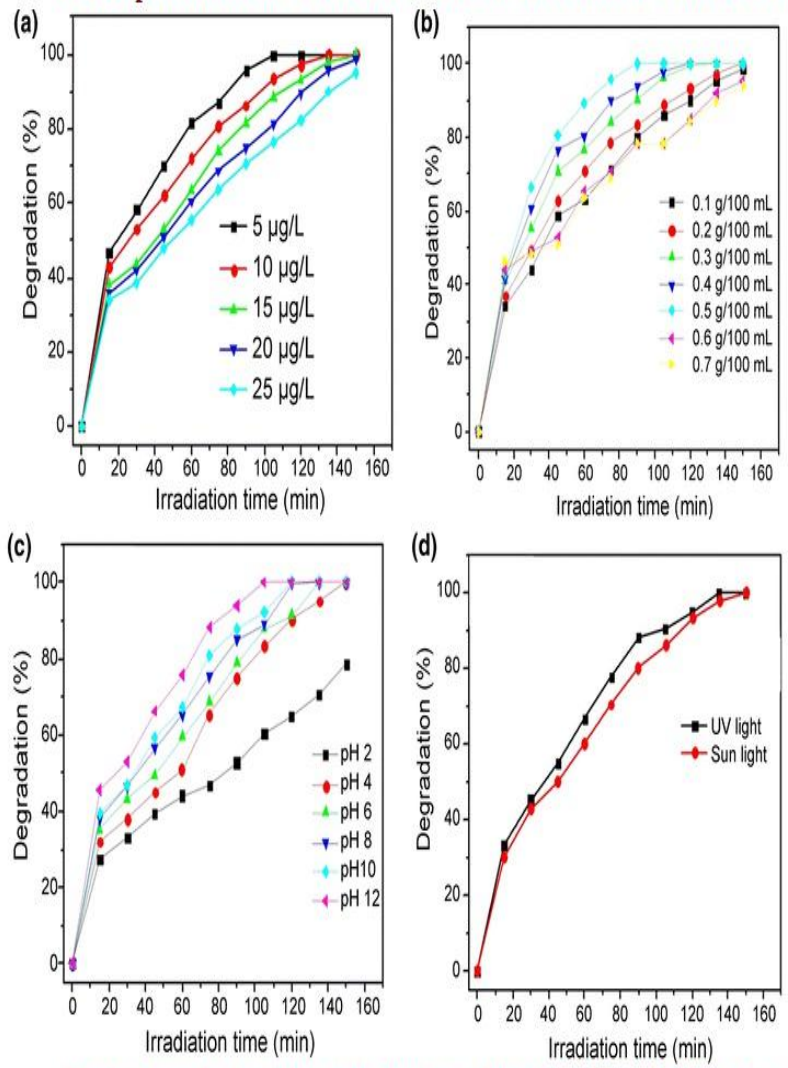

Photodegradation of trypan blue as a function of irradiation time under different experimental conditions

Figure 8:- Green synthesis of CuO NAPs using Rauwolfia serpentina

Udayabhanu et al., [28] also reported solution combustion method. This green approach is very important for the synthesis of cupric oxide nanoparticles (CuO NAPs). Tinospora cordifolia water extract was used in this method. They used XRD, SEM, TEM and UV-visible for morphology and characterization of these nanoparticles. The prepared nanoparticles were monoclinic crystallite structures as shown by XRD. Sponge like structure and large surface area was determined from SEM images. Average crystalline sizes were characterized in TEM which were found to be 6-8 $\mathrm{nm}$. CuO Nps showed potential pathogenic antibacterial activity against $K$. aerogenes, $P$. aeruginosa, E. coli and S. aureus. This method was eco-friendly and nontoxic for the preparation of versatile cupric oxide nanoparticles applying under-utilized remedial plants. 


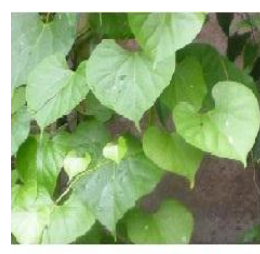

Tinospora cordifolia

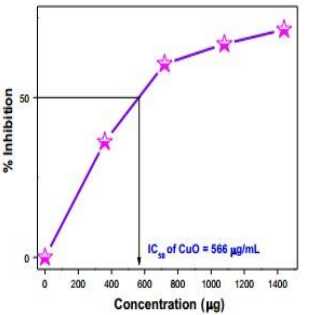

Antioxidant activity of $\mathrm{CuO}$ nanoparticles synthesized using water extract of Tinospora cordifolia leaves by measuring the \%age inhibition of DPPH.

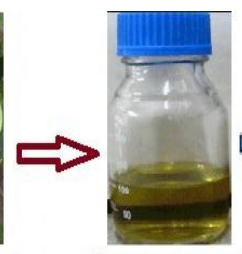

Leaves Extract

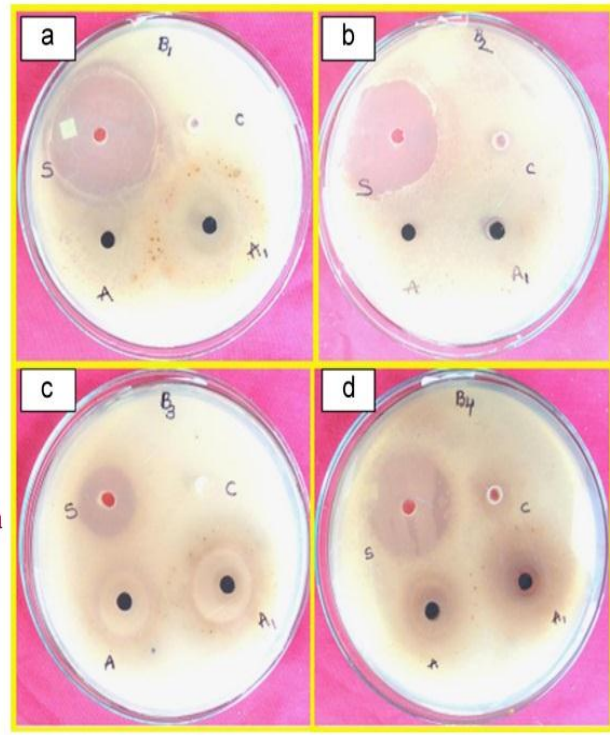

Antibacterial activity of $\mathrm{CuO}$ NAPs by measuring Zone of inhibition of (a) $K$. aerogenes (b) E. coli (c) $P$. aeruginous and (d) $S$. aureus.

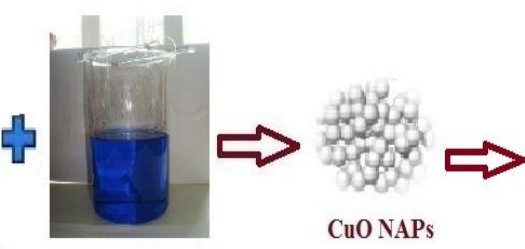

Copper Nitrate
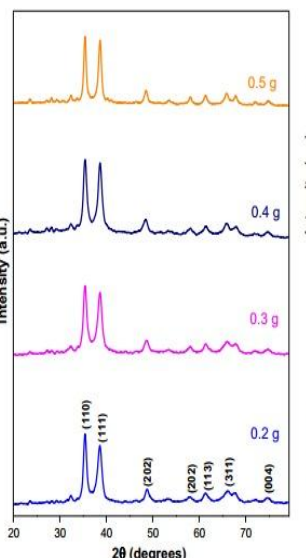

XRD spectra of $\mathrm{CuO}$ NAPs
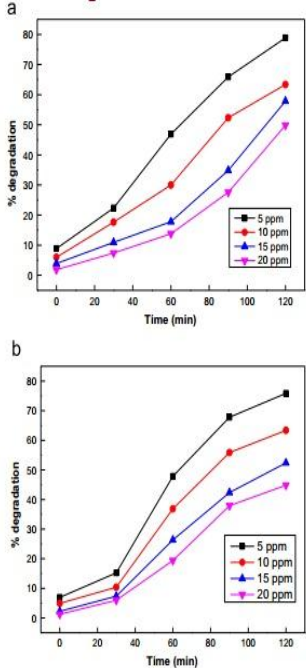

Percentage degradation of (a) UVlight and (b) Sun light in presence of $\mathrm{CuO}$ nanoparticles

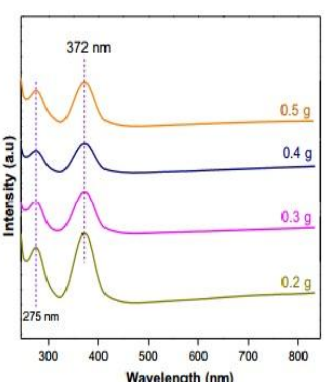

UV-visible spectra of $\mathrm{CuO}$ NAPs
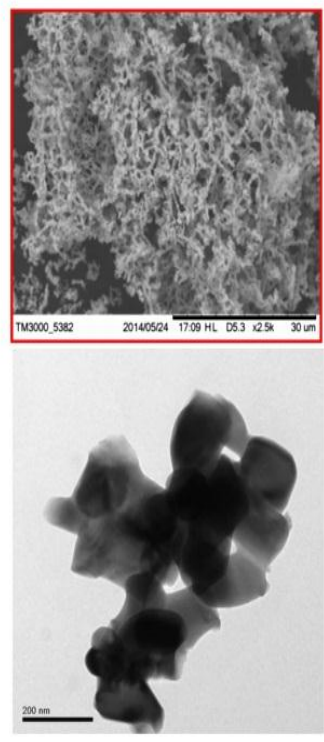

SEM and TEM images of CuO NAPs

Figure 9:- Green synthesis of CuO NAPs using Tinospora cordifolia

Awwad et al., [29] reported synthesis of $\mathrm{CuO}$ nanoparticles by a facile and green method using Malva sylvestris leaf extract. The copper oxide nanoparticles were analyzed to characterize from these techniques FT-IR, SEM, XRD and UV-vis spectroscopy. The average size of crystallites was $14 \mathrm{~nm}$. Important feature of this fabrication was the tunability of the structural features of the cupric oxide nanoparticles by controlling the ratio of the amount of Malva sylvestris leaf extract to copper ions. The synthesized $\mathrm{CuO}$ NPs exhibited important antimicrobial activity against pathogenic strain both Gram-positive and Gram-negative microbes.

Brajesh et al., [30] reported biologically fabricated copper oxide nanoparticles (CuO-NPs) of a desired size. In their study, $10 \mathrm{mM}$ solution of copper nitrate with plant extract Andean blackberry fruit (ABF) and leaf (ABL) was used to prepare cupric oxide nanoparticle. They also assessed its antioxidant activity. CuO-NPs were characterized with the help of UV-visible, TEM and XRD analysis. Antioxidant activities were also reported in their studies.

Reyad-ul-ferdou et al., [39] explained that Abutilon indicum is largely grown in South Asia. A.indicum plant contain large amount of chemical constituents which was utilized in folk medicine. Golden yellow flowers and hairy stem of A. indicum mostly found in Pakistan and India. Abutilon indicum plant leaves were used to cure different diseases such pulmonary, erotic and sedative. Plant bark, seeds, roots and oil were employed in several diseases like astringent diuretic, expectorant, demulcent, anti-inflammatory and anthelmintic. In pile complaints, plant leaves were used for treatment. Flowers of these plant contained significant constituents which enhanced semen in men. 
Alkaloid, Saponins, Amino acid, Flavonoids, Glycosides and steroids was present in plant which was measured in phytochemical analysis. This plant exhibits several potential pharmacological activities.

Acharyulu et al., [31] reported the biological method for green fabrication of CuO nanoparticles they used extract of Phyllanthus amarus leaf which was eco-friendly and non-toxic. Powder XRD analysis showed that CuO nanoparticles had an average size are in $20 \mathrm{~nm}$ while their shape was found to be monoclinic. These particles also proved to have antibacterial properties against Gram +ve (B. subtilis and S. aureus) and Gram -ve (E.coli and P. aeruginosa). Antibacterial action was reportedly much stronger against $B$. subtilis followed by $S$. aureus, $P$. aeruginosa and E.coli.

Abboud et al., [32] also reported biologically oriented fabrication of nanoparticles. They have claimed to have adapted a cheaper, cleaner and efficient technique for fabrication of these nanoparticles. They reported the first time use brown alga (Bifurcaria bifurcata) for the fabrication of copper oxide nanoparticles of dimensions 5-45 $\mathrm{nm}$. They used UV-visible and FT-IR spectrum analysis for the characterization of these nanoparticles. X-ray diffraction was used to characterize the crystallinity of copper oxide nanoparticles. They also reported the antibacterial action of these nanoparticles against gram +ve and gram -ve bacteria.

Rajeshwari et al., [33] explained an eco-friendly method. In this study, Indian medicinal plant Tabernaemontana divaricate extract was used to prepare cupric oxide nanoparticles which are biosynthesis method. 50\% concentration of leaf extract was used to synthesize highly stable and spherical in shape cupric oxide nanoparticles. UV-Vis, XRD, FT-IR, SEM, EDX and TEM these techniques were used to characterize nanoparticles. The average sizes $48 \pm 4 \mathrm{~nm}$ was synthesized. In this research, they observed antimicrobial activity of cupric oxide nanoparticles against urinary tract organisms.

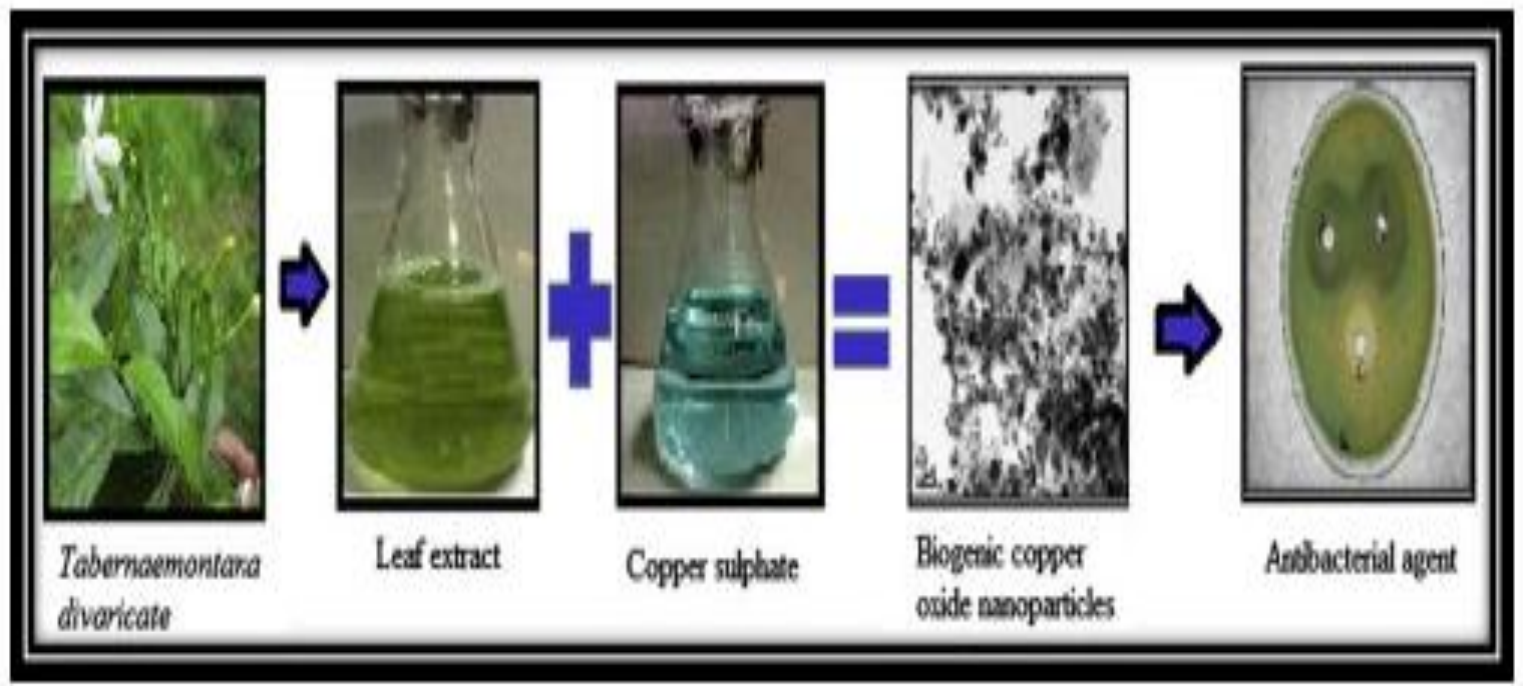

Figure 10:- Green synthesis of CuO NAPs using Tabernaemontana divaricate.

Ali et al., [50] reported a new simple and cost-effective chemical reduction process. In this method these chemicals $\mathrm{CuSO}_{4}, \mathrm{NaOH}$ and $\mathrm{NH}_{3}$ were used in situ to synthesize cuprous oxide nanoparticles on cotton fabric. In reduction process copper sulphate reduce in the presence of cotton fabric which act as reducing agent and help to prepare $\mathrm{Cu}_{2} \mathrm{O}$ in nanometer range as a stabilizer. These techniques such as XRD, SEM and EDX were subjected to characterize synthesized cotton/nano cuprous oxide composite. To observe the alter functional group of cotton in addition with cuprous oxide interaction with cotton fabric were studied using Fourier transforms infrared spectroscopy. Fabric nano composites were used against pathogen like S. aureus and E.coli in antibacterial activity. Moreover, the treated fabric developed into highly hydrophobic and sensed. 


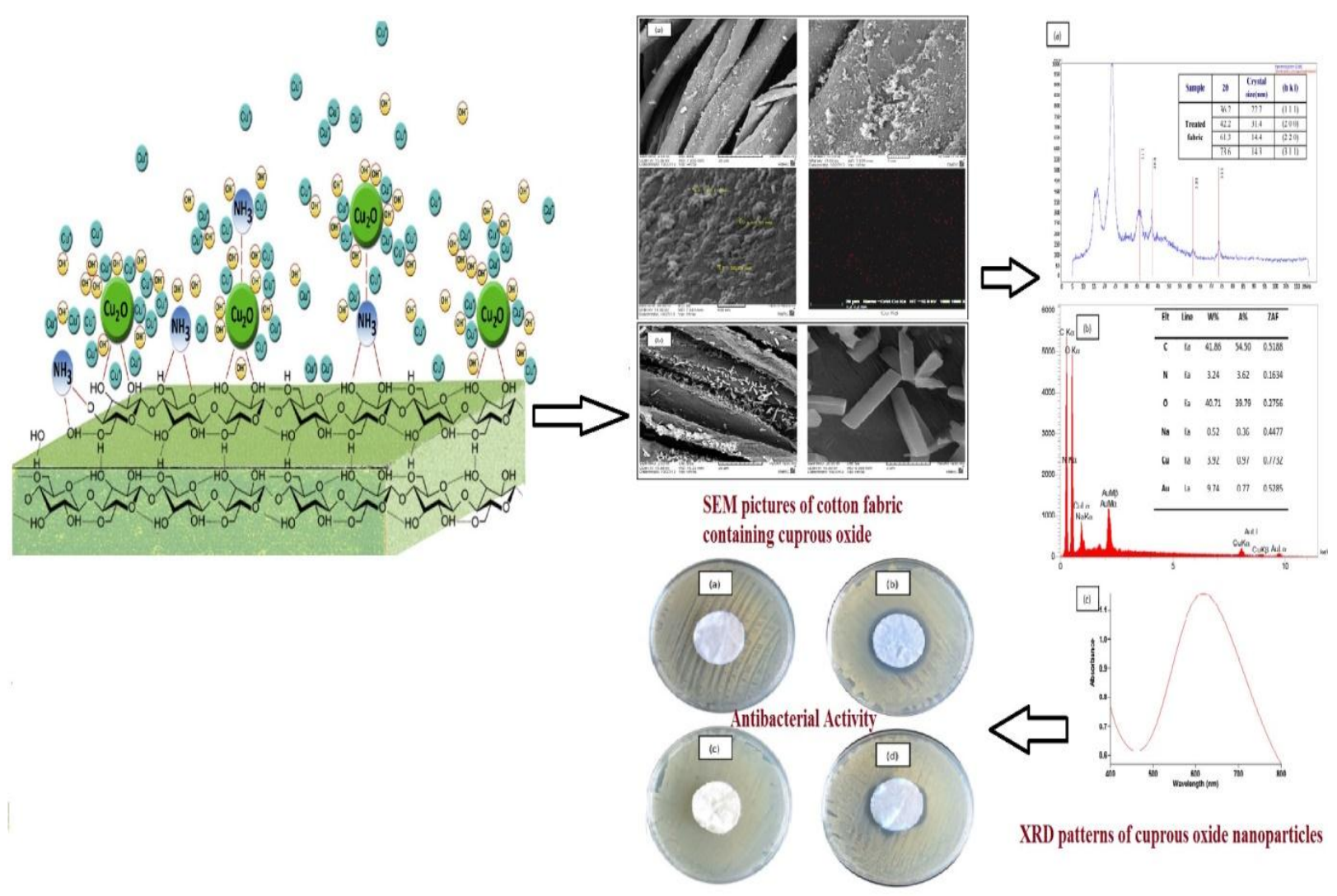

Figure 11:- Synthesis of cuprous oxide nanoparticles on cotton fabric

Prasanta et al., [38] reported green approach toward synthesis of cupric oxide nanoparticles. In this green approach, coffee powder and tea leaves were used as extract for the synthesis of $\mathrm{CuO}$ under microwave irradiations. By using microwave at $540 \mathrm{~W}$, cupric oxide nanoparticles were synthesized to irradiate metal salt and extracts of coffee and tea in 3:1 ratio for 7-8min. SEM, XRD, FT-IR and UV-Vis were used to characterize the prepared particles. To check out the activity of these particles against six human pathogenic organisms. These particles showed excellent activity against these pathogenic bacteria. These $\mathrm{CuO}$ nanoparticles offered several benefits of eco-friendliness and compatibility for pharmaceutical and other biomedical applications.

Renu et al., [35] studied green process in the formation of cupric oxide nanoparticles. $5 \mathrm{mM} \mathrm{CuSO}_{4}$ treated with plant leaves extract (Carica papaya).UV-Vis spectrophotometer was used to measure the kinetics of the reaction. Characterization techniques such as SEM and DLS showed rod shape cupric oxide nanoparticles have average particle size $140 \mathrm{~nm}$. Copper ions reduced in the presence of bioactive functional groups which were examined through FT-IR spectrometer. Crystallite nature of cupric oxide nanoparticles were confirmed from XRD spectra. Cupric oxide nanoparticles have catalytic behavior. Coomassie brilliant blue R-250 dye effectively degraded by cupric oxide nanoparticles in the beneath of sunlight. 


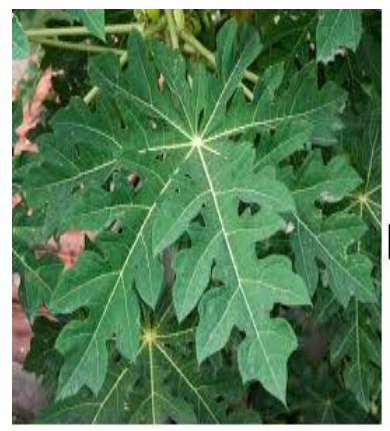

Carica papaya

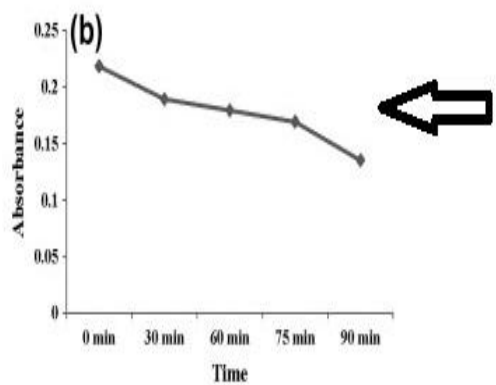

Photocatalytic Activity of CuO NAPs

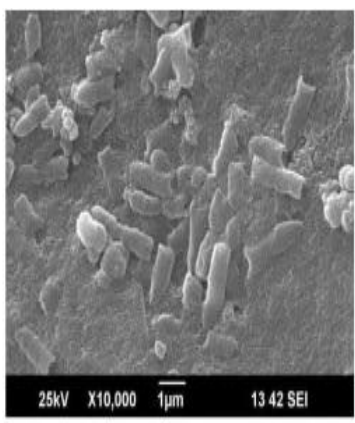

$\mathrm{CuSO} 4$
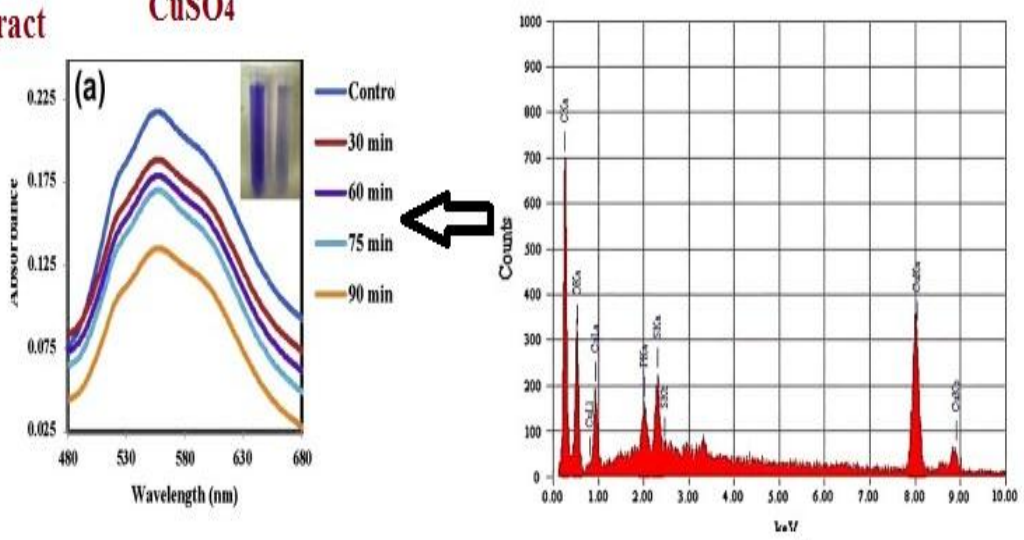

SEM and XRD specrum of CuO NAPs

Figure 12:- Green synthesis of CuO NAPs using Carica papaya

Henam et al., [37] reported use of Centella asiatica leaves extracts for the preparation of copper oxide nanoparticles at room temperature. This method is completely a green and environmental benign method. No toxic and harmful solvent was used in this process. Morphology and size were characterized using SEM, UV-Visible, IR and EDX. $\mathrm{CuO}$ NAPs prepared by this method were suggested to be used for the photo catalytic degradation of methyl orange. This catalytic effect of copper oxide nanoparticles can be contributed to its small size. Nanoparticles have many active sites as compared to the bulk materials because of its greater $\mathrm{S} / \mathrm{V}$ ratio. 


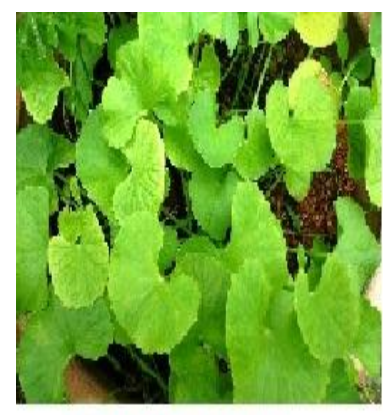

Centella asiatica

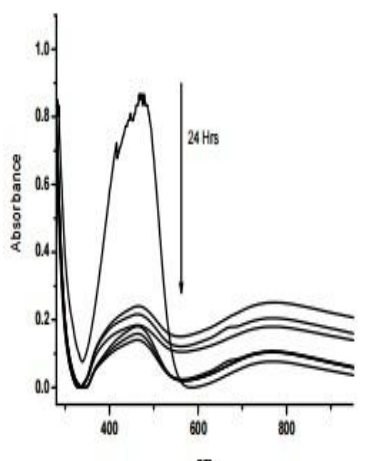

(a)
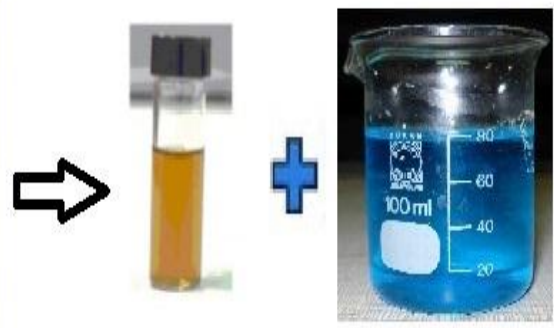

Leaves Extract

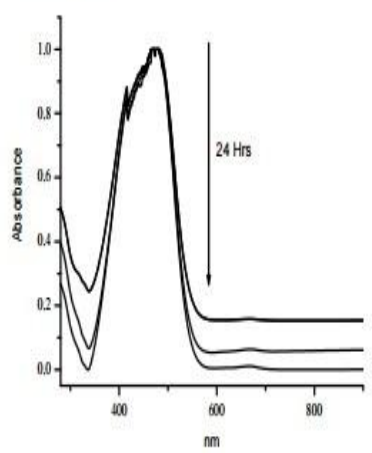

(b)

Copper acetate
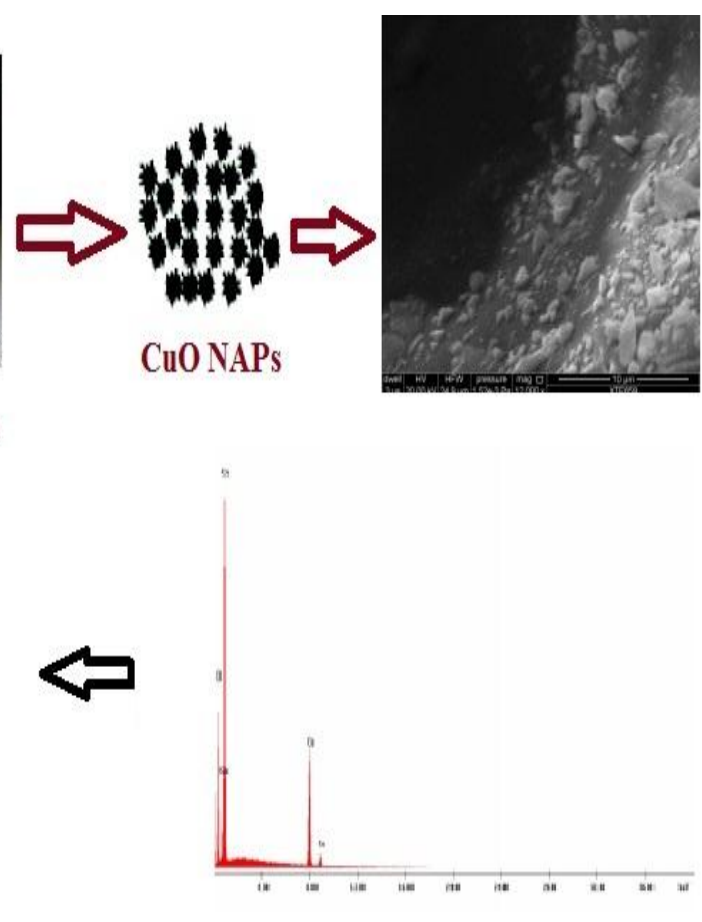

SEM and EDX spectrum of Cu0 NAPs

Photocatalytic Activity of CuO NAPs

Figure 13:- Green synthesis of CuO NAPs using Centella asiatica

Ipsa et al., [20] studied a novel biological method. In this method, they were synthesized Copper nanoparticles using clove. In the presence of clove extract, copper sulphate was reduced to copper nanoparticles. Crystallite structure of cupper nanoparticles was confirmed with XRD. TEM revealed copper nanoparticles size in the range of 5-40nm. Spherical and granular nature of copper nanoparticles was investigated from SEM. Copper nanoparticles peak was characterized to use UV-Visible absorption spectroscope. 


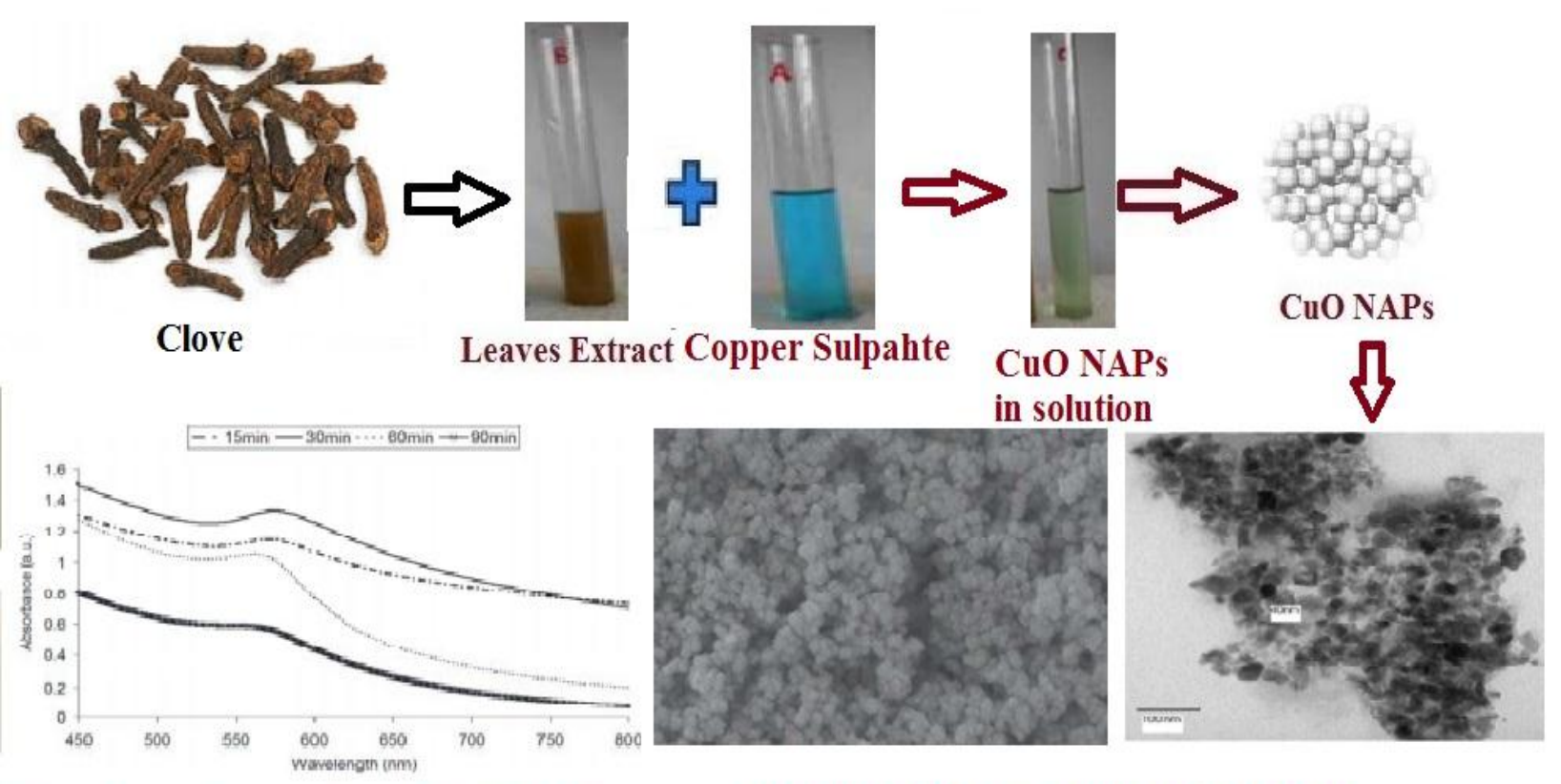

\section{The absorption maxima of CuO NAPs} at $570 \mathrm{~nm}$.

\section{SEM and TEM spectrum of CuO NAPs}

Figure 14:- Green synthesis of CuO NAPs using Syzygium aromaticum (Clove)

Vinod et al., [21] reported that Copper oxide $(\mathrm{CuO})$ nanoparticles have catalytic, antibacterial, photonic, electric, and optical and nanofluid activities and these properties, as all other nano materials depend on aspect ratio and shape of these particles. They showed the fabrication of these nanoparticles by green technology using a natural nontoxic hydrocolloid, Gum karaya, and investigated the antibacterial properties of $\mathrm{CuO}$ nanoparticles.

Gopalakrishnana et al., [34] reported the synthesis of cuprous oxide nanoparticles from Fehling's solution using Tridax procumbens leaf extract. By using green technology, they synthesized nanoparticles which is not involved any toxic chemicals. Plant shoot and leaves contained water soluble carbohydrates which played an important role to copper ion in nano-size cuprous oxide particles. Cuprous oxide nanoparticles surface coated with polyaniline by using $\mathrm{H}_{2} \mathrm{O}_{2}$ as oxidizing agent which create resistance against oxidation of cupric oxide. Synthesize cuprous oxide nanoparticles and PANI coated cuprous oxide were characterized at different analytical techniques such as XRD, SEM, UV-Vis and FT-IR spectroscopy. These particles were evaluated against a variety of surplus infections and toxins in human like E. coli by using disc diffusion method.

Soheyla et al., [40] reported biosynthesis of copper oxide nanoparticles using microorganisms which is an emerging eco-friendly method of fabrication. They synthesized copper oxide NPs having well-defined sizes and shapes. They used green process for the production of nanoparticles. And stabilization was done using $P$. aurantiogriseum, $P$. citrinum and $P$. waksmanii. These stabilizing species were extracted from soil. The NPs fabricated this way had uniform size with spherical shape. They characterized the shape and size by using SEM. DLS was applied to determine the polydispersity of NPs. The outcomes originate by SEM and DLS was further tested by UV-VIS and fluorescence spectrum.

Jiao et al., [36] reported metal hyper-accumulator plant process. From metal hyper-accumulator plant process, $\mathrm{CuO} / \mathrm{ZnO}$ nanoparticles were synthesized. This method commonly used to clean soil polluted toxic and heavy metals. In this study, they suggested that toxic metals were obtained from plant shoots and leaves. These toxic metals transferred from plants to animal and to human beings. So hyper-accumulator plant is better way to prepare nanoparticles. Near copper mine they collected Brassica juncea leaves which utilize as raw chemical to synthesize $\mathrm{Cu} / \mathrm{ZnO}$ nanoparticles. For extraction, ethanol was plant leaves and extracted Copper and Zinc reacted to $\mathrm{HNO}_{3}$ to from $\mathrm{Cu} / \mathrm{Zn}\left(\mathrm{NO}_{3}\right)_{2}$. Sodium hydroxide and ethanol was used to precipitate the $\mathrm{Cu} / \mathrm{Zn}$ chlorophyll. About $97 \mathrm{~nm}$ diameter of synthesize nanoparticles. 
Panneerselvam et al., [41] reported the production of $\mathrm{CuO} / \mathrm{ZnO}$ nano-photocatalyst light assisted degradation of textile dye in an aqueous solution by the wet impregnation technique. The $\mathrm{CuO} / \mathrm{ZnO}$ samples were annealed at the $550{ }^{\circ} \mathrm{C}$ for 5 hours were changed from the purple to grey color, which indicates that $\mathrm{CuO}$ clusters on the $\mathrm{ZnO}$ may not be metallic $\mathrm{Cu}$ but it may be the $\mathrm{CuO}-\mathrm{ZnO}$. Characterization was done by TEM, DRS and XPS analysis which confirms that only $\mathrm{CuO}$ phase is present as the prepared sample.

Nekrasova et al., [42] investigated the effects of copper oxide nanoparticles and copper ions on the activities of antioxidant enzymes, lipid peroxidation rate and photosynthesis. They reported that NPs were accumulated much actively by the plants as compared to the larger particles of same substance. They also showed that the lipids can be oxidized by both copper ions and NPs. Catalase activities were increased by factor of 1.5 to 2.0 with NPs. Rate of photosynthesis was depressed in the presence of concentrated copper ions and in the presence of NPs, whereas in the presence of NPs, same depression was observed at $1.0 \mathrm{mg} / \mathrm{l}$.

Rajendra et al., [43] nanostructured crystalline copper oxide were prepared by the assistance of alcohol/nonionic polymeric surfactant. For characterization TEM, SEM, XRD, FTIR and UV-Vis were used. It was observed that surface area of metal nanoparticles depend upon the ratio of alcohol to anionic surfactant. Greatest surface area was obtained by using methanol in the synthesis process. Catalytic activity was checked for freshly prepared $\mathrm{CuO}$ nanoparticles.

Kooti et al., [44] suggested a simplistic method for preparation of $\mathrm{Cu}_{2} \mathrm{O}$ NPs by reduction of the Fehling's solution, using glucose as the reducing agent. Method was very simple and facile. They used copper sulfate as a starting material and added potassium sodium tartrate in alkaline media for the production of Fehling's solution. Triton- $\mathrm{X}$ 100 was used as the surfactants to control the production of $\mathrm{Cu}_{2} \mathrm{O}$ NPs from Fehling solution. The resulting $\mathrm{Cu}_{2} \mathrm{O}$ NPs were characterized by XRD, SEM, EDX, TEM and FTIR spectroscopy.

Abdul et al., [45] stated a novel suitable method to synthesize of cupric oxide nanoparticles using Phormidium cyanobacterium. They suggested that synthesis of copper oxide nano particles occurs by extracellular hydrolysis of the copper ions by certain anionic reductase produces by bacteria at ambient conditions and aerobic environment. Proteins reduce $\mathrm{Cu}$ (II) into copper oxide nano particles and help stabilization of formed nanoparticles at room temperature. These biologically synthesized NPs were characterized by TEM, SEM, XRD and FTIR analysis.

Guogang et al., [46] attempted successfully the synthesis and characterization of copper oxide (CuO) nanoparticles with respect to the antimicrobial applications. They showed the presence of pure $\mathrm{Cu}$ and $\mathrm{CuO}$ nanoparticles in nanoscaled $\mathrm{CuO}$, produced by thermal plasma technique. Size of particles was found in the range 20 to $95 \mathrm{~nm}$ by using the TEM. The nanoparticles of $\mathrm{CuO}$ were tested against a range of the bacterial pathogens, including S. aureus and $E$. coli and were found effective with minimum bactericidal concentrations ranging from the $100 \mu \mathrm{g} / \mathrm{mL}$ to $5000 \mu \mathrm{g} / \mathrm{mL}$. The antibacterial activity of CuO NAPs to decrease bacterial population up to zero was possible in the presence silver nanoparticles.

Fei et al., [47] reported synthesis of $\mathrm{CuO}$ particles by hydrothermal method. They investigated the influence of the hydrothermal temperature and time on growth of NAPs. XRD, SEM, HRTEM, TEM, and ED were used for the characterization. The flower-like structures showed high chemiluminescence intensities and the reactivates for the CO oxidation.

Dongyun et al., [48] studied TritonX-100 based water-in-oil reverse micelles system. In this research, cupric oxide nanoparticles were synthesized using TritonX-100. Different techniques were employed to characterize nanoparticles such as XRD and TEM. The ratio of water to surfactant played an important role in synthesis of grain size, morphology and distribution. The control effect of water content dissolved in reverse micelles was associated to the improvement of the exchange rate of reactants among micelles. This control effect also depends upon the relevant change in the interfacial film flexibility of reverse micelles with the increasing amount of water in the micro emulsion.

Chun-Hong et al., [49] reported the synthesis CuO NAPs with the estimated average sizes of 40 to 420 nanometers. They adapted seed-mediated method in the aqueous solution. After 2 hours, nanocubes are synthesized at room. Well-defined $\mathrm{Cu}_{2} \mathrm{O}$ nanocubes were synthesized to react $\mathrm{CuSO}_{4}$ with sodium dodecyl sulfate reaction mixture. The nanocubes most probably, formed by the controlled aggregation of the $\mathrm{Cu}_{2} \mathrm{O}$ particles. The surface rebuilding of 
nanocubes influenced through SDS surfactant and the sulfate ions. Optical characters showed nanocubes are smaller than the $100 \mathrm{~nm}$ absorbs at 490 nanometer. Absorption band at the 515-525 $\mathrm{nm}$ showed that the size nanocubes were larger than $200 \mathrm{~nm}$.

\section{Conclusion:-}

Many cost- effective and eco-friendly methods to synthesis metal oxide nanoparticles like Copper Oxide are available in the literature. Sufficient volume of published literature is available on the synthesis of CuO NAPs through green routes. Among plants, angiosperm species has been widely used in comparison with the other sources. Several characterizations methods and techniques have been used for CuO NAPs synthesis and confirmation. The $\mathrm{CuO}$ NAPs synthesized using biological reducing and capping agents have shown wide variation in shape and size. Among applications, the anti-microbial action of $\mathrm{CuO}$ NAPs has been widely studied. Various methods used to carry out antibacterial study and elucidate mechanism of anti-microbial and antioxidants have been developed. The results, however, are conflicting and there is a need for more work to resolve this issue. The potential of CuO NAPs for their use as drug carriers in cancer therapy, as biosensors for metabolites and pollutants, as catalyst etc. is quite high and requires intensive and integrated research activity for harnessing it.

\section{Acknowledgement:-}

This work was supported by Department of Chemistry, University of Management and Technology, Lahore Pakistan.

\section{Conflict of Interest:-}

There is no found conflict of interest.

\section{References:-}

1. Balzani, V.; Nanoscience and nanotechnology: a personal view of a chemist. Small. 2005, 1(3): $278-283$.

2. Bednorz, J. G.; and Muller, K. A.; Possible high Tech superconductivity in the Ba-La-Cu-O system, Ten Years of Superconductivity: 1980-1990, Springer Netherlands, 1986, 267-271.

3. $\mathrm{Ng}$, C.H.B.; Wai, Y. F.; Shape evolution of $\mathrm{Cu}_{2} \mathrm{O}$ nanostructures via kinetic and thermodynamic controlled growth. The Journal of Physical Chemistry B. 2006; 110(42): 20801-20807.

4. Ren, G.; Hu, D.; Cheng, E. W.; Vargas-Reus, M. A.; Reip, P.; Allaker, R. P.; Characterization of copper oxide nano particles for antimicrobial applications. International Journal of Antimicrobial Agents. 2009; 33(6): 587590.

5. Kwak, K.; Chongyoup, K.; Viscosity and thermal conductivity of copper oxide nanofluid dispersed in ethylene glycol. Korea-Australia Rheology Journal. 2005; 17(2): 35-40.

6. Sankar, R.; Manikandan, P.; Malarvizhi, V.; Fathima, T.; Shivashangari, K. S.; Ravikumar, V.; Green synthesis of colloidal copper oxide nanoparticles using Carica papaya and its application in photocatalytic dye degradation. Spectrochimica Acta Part A: Molecular and Biomolecular Spectroscopy. 2014; 121: 746-750.

7. Yallappa, S.; Manjanna, J.; Sindhe, M. A.; Satyanarayan, N. D.; Pramod, S. N.; Nagaraja, K.; Microwave assisted rapid synthesis and biological evaluation of stable copper nanoparticles using T. arjuna bark extract. Spectrochimica Acta Part A: Molecular and Biomolecular Spectroscopy. 2013; 110: 108-115.

8. Khan SA, Shahid S, Ahmad W, Ullah S. Pharmacological Importance of Clerodendrum Genus: A Current Review. International Journal of Pharmaceutical Science and Research. 2017; 2(2): 22-30.

9. Khan SA, Rasool N, Riaz M, Nadeem R, Rashid U, Rizwan K, Zubair M, Bukhari IH, Gulzar T. Evaluation of Antioxidant and Cytotoxicity Studies of Clerodendrum inerme. Asian Journal of Chemistry. 2013; 25(13):74577462.

10. Khan SA, Jameel M, Kanwal S, Shahid S. Medicinal Importance of Allium Species: A Current Review. International Journal of Pharmaceutical Science and Research. 2017; 2(3): 29-39.

11. Khan SA, Shahid S, Khan ZA, Iqbal A. Assessment of Stabilization of Canola Oil, Free Radical Scavenging and Cytotoxic Potential of Peucedanum graveolens (roots). International Journal of Scientific and Research Publications. 2016; 6(3): 529-535.

12. Khan SA, Shahid S, Jameel M, Ahmad A. In vitro Antibacterial, Antifungal and GC-MS Analysis of Seeds of Mustard Brown. International Journal of Pharmaceutical Chemistry. 2016; 6(4):107- 115.

13. Ijaz F, Shahid S, Khan SA, Ahmad W, Zaman S. Green Synthesis of Copper oxide Nanoparticles using Abutilon indicum Leaf Extract: Antimicrobial, Antioxidant and Photocatalytic Dye Degradation Activities. Tropical Journal of Pharmaceutical Research. 2017; 16(4): 743-753. 
14. Das, S. K.; Khan, M. M. R.; Guhab, A. K.; Naskar, N.; Bioinspired fabrication of silver nanoparticles on nanostructured silica: characterization and application as a highly efficient hydrogenation catalyst. Green Chemistry. 2013; 15: 2548-2557.

15. Iravani, S.; Green synthesis of metal nanoparticles using plants. Green Chemistry. 2011; 13(10): 2638-2650.

16. Raveendran, P.; Fu, J.; Wallen, S.; Completely "green" synthesis and stabilization of metal nanoparticles. Journal of the American Chemical Society. 2003; 125(46): 13940-13941.

17. Parashar, V.; Parashar, R.; Sharma, B.; Pandey, A. C.; Parthenium leaf extract mediated synthesis of silver nanoparticles: a novel approach towards weed utilization. Digest Journal of Nanomaterials and Biostructures. 2009; 4(1): 45-50.

18. Sankar, R.; Karthik, A.; Prabu, A.; Karthik, S.; Shivashangari, K.S.; Ravikumar, V.; Origanum vulgare mediated biosynthesis of silver nanoparticles for its antibacterial and anticancer activity. Colloids and Surfaces B: Biointerfaces. 2013; 108: 80-84.

19. Schrofel, A.; Kratošová, G.; Šafařík, I.; Šafař́ková, M.; Raška, I.; Shor, L. M.; Applications of biosynthesized metallic nanoparticles-A review. Acta biomaterialia. 2014; 10(10): 4023-4042.

20. Ipsa, S.; Nayak, P.L.; Synthesis of Copper Nanoparticles Using Syzygium aromaticum (Cloves) Aqueous Extract by Using Green Chemistry. World Journal of Nano Science \& Technology. 2013; 2(1): 14-17.

21. Vinod, V.; Thekkae, P.; Miroslav, C.; Green synthesis of copper oxide nanoparticles using Gum karaya as a biotemplate and their antibacterial application. International Journal of Nanomedicine. 2013; 8: 889-898.

22. Fatih, D.; Ismail, O.; Fatma, O. K.; Chamomile flower extract-directed $\mathrm{CuO}$ nanoparticle formation for its antioxidant and DNA cleavage properties. Materials Science and Engineering C. 2016; 60:333-338.

23. Naika, H. R.; Lingarajua, K.; Manjunathb, K.; Danith, K.; Nagarajuc, G.; Sureshd, D.; Nagabhushana, H.; Green synthesis of $\mathrm{CuO}$ nanoparticles using Gloriosa superba L.extract and their antibacterial activity. Journal of Taibah University for Science. 2015; 9: 7-12.

24. Jayakumarai, G.; Gokulpriya, C.; Sudhapriya, R.; Sharmila, G.; Muthukumaran, C.; Phytofabrication and characterization of monodisperse copper oxide nanoparticles using Albizia lebbeck leaf extract. Applied Nanoscience. 2015; 5: 1017-1021.

25. Kumar, P. P. N. V.; Shameem, U.; Pratap, K.; Kalyani, R. L.; Pammi, S. V. N.; Green Synthesis of Copper Oxide Nanoparticles Using Aloe vera Leaf Extract and Its Antibacterial Activity Against Fish Bacterial Pathogens. Bio Nano Science. 2015; 5: 135-139.

26. Lingaraju, K.; Naika, H.R.; Manjunath, K.; Nagaraju, G.; Suresh, D.; Nagabhushana, H.; Rauvolfia serpentinaMediated Green Synthesis of $\mathrm{CuO}$ Nanoparticles and Its Multidisciplinary Studies. Acta Metallurgica Sinica (English Letters). 2015; 28(9): 1134-1140.

27. Gowdhami, M.; Balagurunathan, R.; Sarkar, B.; Ayyasamy, P. M.; Evaluation of antibacterial activity of plant mediated $\mathrm{CaO}$ nanoparticles using Cissus quadrangularis extract. Journal of Photochemistry \& Photobiology, B: Biology. 2016; 155: 28-33.

28. Udayabhanu,; Nethravathi, P.C.; PavanKumar, M.A.; Suresh, D.; Lingaraju,K.; Rajanaika, H.; Nagabhushana, H.; Sharma, S.C.; Tinospora cordifolia mediated facile green synthesis of cupric oxide nanoparticles and their photocatalytic, antioxidant and antibacterial properties. Materials Science in Semiconductor Processing. 2015; 33: 81-88.

29. Awwad, A.M.; Albiss, B.A; Salem N.M; Antibacterial Activity of synthesized Copper Oxide Nanoparticles using Malva sylvestris Leaf Extract. Sikkim Manipal University (SMU) Medical Journal. 2015; $2(1)$ : 91 - 101.

30. Brajesh, K.; Kumari, S.; Luis, C.; Alexis, D.; Yolanda, A.; Biofabrication of copper oxide nanoparticles using Andean blackberry (Rubus glaucus Benth.) fruit and leaf. Journal of Saudi Chemical Society. 2015; 9: 1-6.

31. Acharyulu, N. P. S.; Dubey, R. S.; Swaminadham, V.; Kalyani, R. L.; Pratap, K.; Pammi, S. V. N.; Green Synthesis of $\mathrm{CuO}$ Nanoparticles using Phyllanthus Amarus Leaf Extract and their Antibacterial Activity Against Multidrug Resistance Bacteria. International Journal of Engineering Research \& Technology. 2014; 3(4): 639- 641 .

32. Abboud,Y.; Saffaj, T.; Chagraoui, A.; El Bouari, A.; Brouzi, K.; Tanane, O.; Ihssane, B.; Biosynthesis, characterization and antimicrobial activity of copper oxide nanoparticles (CONPs) produced using brown alga extract (Bifurcaria bifurcata). Applied Nanoscience. 2014; 4(5): 571-576.

33. Rajeshwari, S.; Pattanathu, K.S.M.; Rahman, P. R.; Hasna A. S.; Venckatesh, R.; Biogenic copper oxide nanoparticles synthesis using Tabernaemontana divaricate leaf extract and its antibacterial activity against urinary tract pathogen. Spectrochimica Acta Part A: Molecular and Biomolecular Spectroscopy. 2014; 133: $178-181$. 
34. Gopalakrishnana, K.; Rameshb, C.; Ragunathanb, V.; Thamilselvana, M.; Antibacterial Activity Of CuO Nanoparticles On E. Coli Synthesized From Tridax procumbens Leaf Extract And Surface Coating With Polyaniline. Digest Journal of Nanomaterials and Biostructures, 2012; 7(2): 833-839.

35. Renu, S.; Perumal, M.; Viswanathan, M.; Tajudeennasrin, F. K. S. S.; Vilwanathan, R.; Green synthesis of colloidal copper oxide nanoparticles using Carica papaya and its application in photocatalytic dye degradation. Spectrochimica Acta Part A: Molecular and Biomolecular Spectroscopy. 2014; 121: 746-750.

36. Jiao, Q.; Chunqiu, L.; Qiao, C.; Xing, Y.; Carbon nanotubes and $\mathrm{Cu}-\mathrm{Zn}$ nanoparticles synthesis using hyperaccumulator plants. Environmental chemistry letters. 2012; 10(2): 153-158.

37. Henam, S. D.; Thiyam, D. S.; Synthesis of Copper Oxide Nanoparticles by a Novel Method and its Application in the Degradation of Methyl Orange. Advance in Electronic and Electric Engineering, 2014; 4(1): 83-88.

38. Prasanta, S.; Mitali, S.;Debasish, M.; Microwave synthesis of copper oxide nanoparticles using tea leaf and coffee powder extracts and its antibacterial activity. Journal of Nanostructure in Chemistry. 2014; 4(1): 1-6.

39. Reyad-ul-ferdou, M.; Mehedi, R.; Mahamud, M.K.; Sharmi, S.A.; Sohel, M. D.; Pharmacologicals and Phytochemicals Potential of Abutilon indicum: A Comprehensive Review. American Journal of Bio Science. 2015; 3(2-1):5-11.

40. Soheyla, H.; Hamed, B.; Eshrat, G.; Farzaneh, N.; Green Synthesis Of Copper Oxide Nanoparticles Using Penicillium Aurantiogriseum, Penicillium Citrinum And Penicillium Waksmanii. Digest Journal of Nanomaterials and Biostructures. 2012; 7(3): 999 - 1005.

41. Panneerselvam, S.; Ramaswamy, S.; Jerry, J.W.; Sambandam, A.; Synthesis of CuO-ZnO nanophotocatalyst for visible light assisted degradation of a textile dye in aqueous solution. Chemical Engineering Journal. 2011; 171:136-140.

42. Nekrasovaa, G. F.; Ushakovaa, O. S.; Ermakovb, A. E.; Uiminb, M. A.; Byzov, I. V.; Effects of Copper(II) Ions and Copper Oxide Nanoparticles on Elodea densa Planch. Russian Journal of Ecology. 2011; 42(6):458-463.

43. Rajendra, S.; Prathap, M.U.A.; Rajkumar, K.; Morphologically controlled synthesis of copper oxides and their catalytic applications in the synthesis of propargylamine and oxidative degradation of methylene blue. Colloids and Surfaces A: Physicochemical and Engineering Aspects. 2011; 392(1): 271- 282.

44. Kooti, M.; Matouri, L.; Fabrication of nanosized cuprous oxide using fehling's solution. Scientia Iranica. 2010, 17(1): 73-78.

45. Abdul, R.; Amri, I.; Desi, J.; Stella, M.; Hanggara, S.; Synthesis Of Copper Oxide Nano Particles By Using Phormidium Cyanobacterium. Indonesian Journal of Chemistry. 2009; 9(3): 355-360.

46. Guogang, R. Dawei, H.; Eileen,W.C.; Cheng, M. A.; Vargas-Reus, P. R.; Robert, P.; Allaker.; Characterisation of copper oxide nanoparticles for antimicrobial applications. International Journal of Antimicrobial Agents. 2009; 33:587-590.

47. Fei, T.; Wenqing, Y.; Youfei, Z.; Yutao, M.; Yang, T.; Tongguang, X.; Shuhui, L.; Yongf, Z.; Synthesis of flower-like $\mathrm{CuO}$ nanostructures as a sensitive sensor for catalysis. Sensors and Actuators B. 2008; 134:761768.

48. Dongyun, H.; Huaiyu, Y.; Chengyun, Z.; Fuhui, W.; Controlled synthesis of CuO nanoparticles using TritonX100 based water-in-oil reverse micelles. Powder Technology. 2008; 185(3): 286-290.

49. Chun-Hong, K.; Chiu-Hua, C.; Michael, H. H.; Seed-Mediated Synthesis of Monodispersed $\mathrm{Cu}_{2} \mathrm{O} \mathrm{Nanacubes}$ with Five Different Size Ranges from 40 to 420 nm. Advanced Functional Materials. 2007, 17:3773-3780.

50. Ali, S.; Majid, M.; Nasrin, S.; Synthesis of nano $\mathrm{Cu}_{2} \mathrm{O}$ on cotton: Morphological, physical, biological and optical sensing characterizations. Carbohydrate Polymers. 2014; 110: 489-498. 